\title{
A 0.01 Resolving TRMM PR Precipitation Climatology
}

\author{
M. HIROSE AND K. OKADA ${ }^{\mathrm{a}}$ \\ Faculty of Science and Technology, Meijo University, Nagoya, Japan
}

(Manuscript received 5 October 2017, in final form 6 May 2018)

\begin{abstract}
In this study, rainfall data are prepared at a $0.01^{\circ}$ scale using 16-yr spaceborne radar data over the area of $36.13^{\circ} \mathrm{S}-36.13^{\circ} \mathrm{N}$ as provided by the Tropical Rainfall Measuring Mission (TRMM) Precipitation Radar (PR). A spatial resolution that is finer than the field of view is obtained by assuming rainfall uniformity within an instantaneous footprint centered on the PR footprint geolocation. These ultra-high-resolution data reveal local rainfall concentrations over slope areas. A new estimate of the maximum rainfall at Cherrapunji, India, was observed on the valley side, approximately $5 \mathrm{~km}$ east of the gauge station, and is approximately $50 \%$ higher than the value indicated by the $0.1^{\circ}$-scale data. A case study of Yakushima Island, Japan, indicates that several percent of the sampling error arising from the spatial mismatch may be contained in conventional $0.05^{\circ}$-scale datasets generated without footprint areal information. The differences attributable to the enhancement in the resolution are significant in complex terrain such as the Himalayas. The differences in rainfall averaged for the $0.1^{\circ}$ and $0.01^{\circ}$ scales exceed $10 \mathrm{~mm}$ day $^{-1}$ over specific slope areas. In the case of New Guinea, the mean rainfall on a mountain ridge can be 30 times smaller than that on an adjacent slope at a distance of $0.25^{\circ}$; this is not well represented by other high-resolution datasets based on gauges and infrared radiometers. The substantial nonuniformity of rainfall climatology highlights the need for a better understanding of kilometer-scale geographic constraints on rainfall and retrieval approaches.
\end{abstract}

\section{Introduction}

An accurate understanding of local precipitation events and climate gradients is important for various applications in multiple geographic regions (e.g., Deblauwe et al. 2016; Funk et al. 2015a; Kirschbaum et al. 2017). In particular, spatiotemporal variation is large over mountainous areas, and finescale features have been investigated by a number of observational studies (Isotta et al. 2014; Minder et al. 2008). Gauge-based gridded datasets (Schneider et al. 2014; Fick and Hijmans 2017) and scale-free point data (Wang et al. 2016) are useful in dealing with areal rainfall over an entire land surface; however, significant uncertainties persist because of the limited number of observation sites and resulting errors due to interpolation schemes, as reported by a number of researchers (e.g., Daly et al. 2008). Meanwhile, high-resolution global precipitation datasets based on microwave and infrared radiometers are available (e.g., GEO 2005). Even though

\footnotetext{
${ }^{\text {a }}$ Current affiliation: Chuozuken Co., Ltd., Nagoya, Japan.
}

Corresponding author: Masafumi Hirose, mhirose@meijo-u.ac.jp satellite data fill spatial and temporal gaps, they include uncertainties associated with the vertical structure of precipitation and retrieval differences depending on the surface type and the spatial resolution (Mega and Shige 2016; Shige and Kummerow 2016; Guilloteau et al. 2017; Seo et al. 2015). A kilometer-scale proxy of precipitation can be obtained by infrared radiance based on geostationary satellites (Funk et al. 2015a,b). The validation of such gauge-calibrated satellite data could help improve our understanding of precipitation and the development of various practical uses for such data (Maidment et al. 2017; Mei et al. 2016; Mott and Lehning 2010; Shea et al. 2015; Vernimmen et al. 2012).

Unlike other sensors, the Precipitation Radar (PR) on the Tropical Rainfall Measuring Mission (TRMM) satellite directly observed precipitation echoes in various regions over a period of more than $16 \mathrm{yr}$ (Hirose et al. 2017b). The long-term operation of the PR was realized using an orbit boost, maintaining the orbital altitude using fuel intended for a controlled reentry, and switching between primary and redundant systems (NASA 2007). The large amount of data produced has expanded our understanding of sharp spatial fluctuations in rainfall by reducing sampling errors (Biasutti et al. 2012; Nesbitt and 
Anders 2009; Hirose et al. 2017a,b). The highest grid resolution of previous PR analyses was $0.05^{\circ}$, which is comparable to a footprint size of $5 \mathrm{~km}(4.3 \mathrm{~km}$ before the orbit boost in August 2001). Several studies have utilized a $0.1^{\circ}$ grid spacing to ensure sampling sufficiency. Hirose et al. (2017b) demonstrated that TRMM PR has advantages in the detection of orographic and coastal rainfall at the $0.1^{\circ}$ scale. Even though these footprintscale gridded data provide the highest-resolution rainfall information of global estimates, comparative studies with regional observations highlight the need for even finerscale datasets to better understand local phenomena and improve the nonuniformity of the data (e.g., Zhang et al. 2004; Kirstetter et al. 2013; Heymsfield et al. 2000). To accurately understand orographic rainfall and the local water budget, the relationship between ground observations and model outputs should be further evaluated by examining the kilometer-scale spatial representativeness of the data (Karger et al. 2017). A further understanding of the present limitations and the need for global rainfall information at higher resolution is also required in discussions of sensor specifications for future Earth observation satellite plans.

The estimated value for each instantaneous field of view is generally attributed to the grid box containing the midpoint of the footprint. Therefore, a higher grid resolution corresponds to fewer samples per grid box. One issue in producing finescale datasets is the mismatch in the spatial coverage of individual footprints and the corresponding grid box. Here, we develop a subfootprint database without any deterioration in the footprint-extent values caused by the finescale mapping. In this study, a kilometer-scale representation of the orographic precipitation gradients is examined in comparison with a conventional TRMM PR dataset and other high-resolution gauge-based datasets. The purpose of this study is to understand geographical rainfall features and demonstrate the need for kilometer-scale rainfall data.

\section{Data and methods}

This study primarily uses surface rainfall rates estimated by the TRMM PR 2A25 version 7 algorithm (Iguchi et al. 2009, 2010). The data for 16 years (1998-2013) are compiled, and the long-term average is referred to as the rainfall climatology in this paper, even though (i) it is not really of climatology length and (ii) both rain and snow are observed by the PR. Figure 1 illustrates the data processing procedure. PR-A in this figure is our proposed dataset. PR-B is based on a conventional method archiving data to only the centroid location of the footprint. Instantaneous rainfall

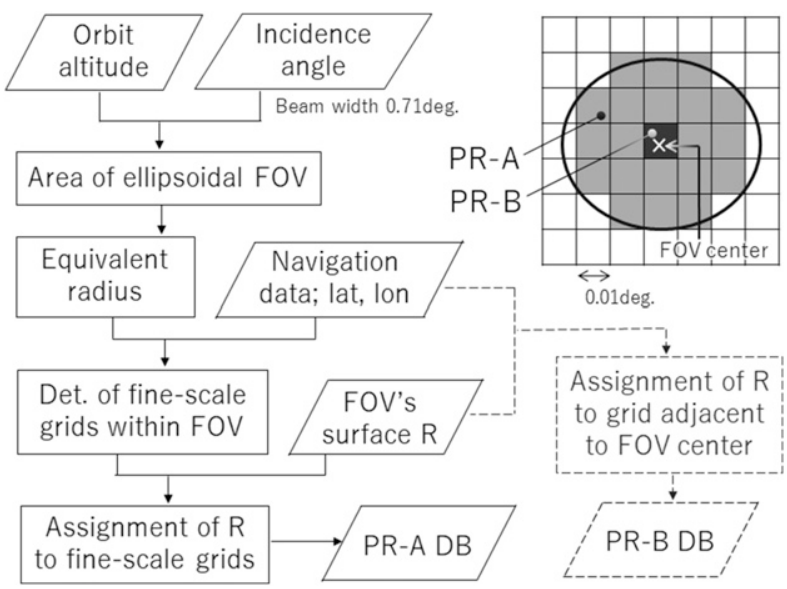

FIG. 1. Flow of the PR-A and PR-B databases generated from the TRMM PR 2A25 data.

rates are assigned equally to all $0.01^{\circ}$ grid boxes within the footprint (diameter $\simeq 5 \mathrm{~km}$ ). Given that the size of each footprint varies by region and incidence angle, the effective diameter is calculated from the area of the ellipse. The major and minor radii of the individual footprints are obtained from the orbit altitude, zenith angle, and beamwidth $\left(0.71^{\circ}\right)$. The target grid boxes are determined from the diameter of the area-equivalent circle and the centroid location of the footprint. In this study, for simplicity, an area-equivalent circle is substituted for the actual elliptical footprint. The largest difference between the major radii and the areaequivalent radii is approximately $0.12 \mathrm{~km}$ at the swath edge for the period after the orbital boost in 2001 (and it is less before the boost). All $0.01^{\circ}$ grid boxes that are more than half covered by the equivalent circular footprint are given its value. On average, one footprint is divided into 18.8 and 19.8 subsamples at the $0.01^{\circ}$ scale in the $10^{\circ} \mathrm{S}-10^{\circ} \mathrm{N}$ tropics and $34^{\circ}-35^{\circ} \mathrm{N}$ midlatitudes, respectively.

Ignoring rainfall inhomogeneity within the footprint can be a significant source of error for the representativeness and the path-integrated attenuation (PIA), particularly for the retrieval of the edge features of the instantaneous rainfall distribution (Durden et al. 1998; Harris et al. 2003; Tustison et al. 2003; Zhang et al. 2004; Kirstetter et al. 2015). The 2A25 version 7 algorithm uses the coefficient of variation of specific attenuation $\left(k_{p}\right)$ in a plane perpendicular to the range direction within the beam as an adjustable parameter related to the nonuniform beam filling (NUBF) effect [details can be found in Iguchi et al. (2009) and TRMM Precipitation Radar Team (2011)]. The correction reduces the underestimation at high rainfall rates (Kirstetter et al. 2013; Iguchi et al. 2009). In this study, an additional 


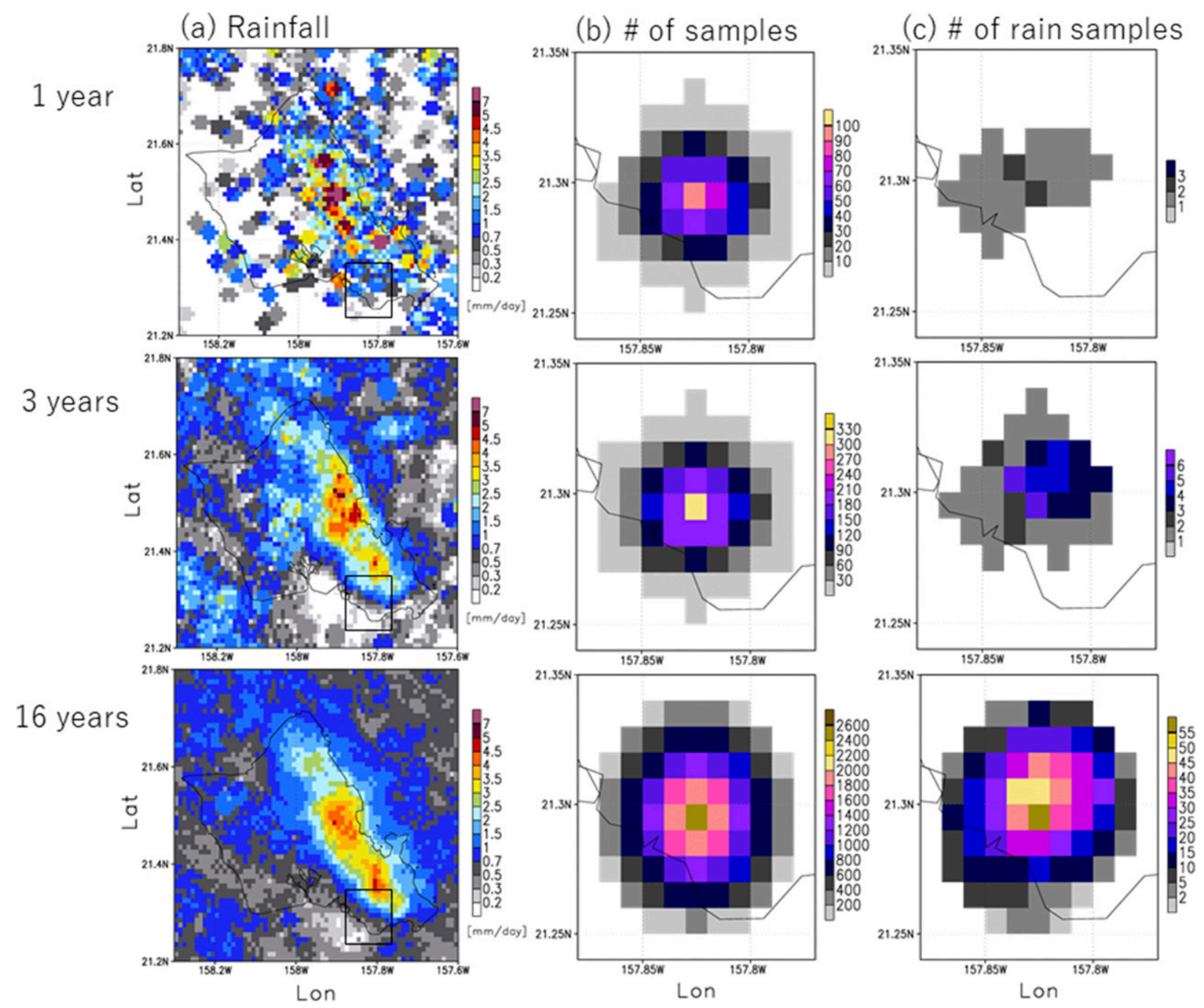

FIG. 2. Sampling properties of the $0.01^{\circ}$-scale PR-A statistics during the periods of (top) 1998, (middle) 1998-2000, and (bottom) 1998-2013. (a) Rainfall over the island of Oahu. (b) Total number of samples conditioned on the overpass at a grid box $\left(21.295^{\circ} \mathrm{N}\right.$, $157.825^{\circ} \mathrm{W}$ ). (c) As in (b), but for the rain samples. The rectangular areas in (a) indicate the regions that are analyzed in (b) and (c).

NUBF correction is not implemented for simplicity and to maintain consistency with the $2 \mathrm{~A} 25$ product. Note that the blurring effect due to the sensor resolution can be large for quantitative estimates of abundant rainfall concentrated in a fairly small area; however, it is assumed to be relatively small for the detection of spatially coherent climatological features.

The short-term average consists of a small number of rain samples. The data accumulation effect on the $0.01^{\circ}$ scale PR-A rainfall dataset is examined for a case around Honolulu, Hawaii, on the island of Oahu, known for having plentiful rainfall near the Ko'olau Mountain Range on the windward (eastern) side and low rainfall on the leeward side. Figure 2a illustrates that individual snapshots filled with rain signals do not overlap each other for a period of $1 \mathrm{yr}$ over the greater part of the lowrainfall areas. Traces of the footprint are seen as circular patterns even for 3-yr data, indicating artificial spatial discontinuity because of insufficient rain samples. The spatial gradient appears to be continuous for the longterm data. Figure $2 b$ shows the distribution of all the samples when the instantaneous footprint includes the center grid box of this panel, located near the eastern mountains. The numbers of samples at the center grid box near the eastern mountains are 95, 301, and 2555 for 1998, 1998-2000, and 1998-2013, respectively. The distribution of the samples shows that a data point affects the statistics in the neighboring grids, and vice versa, as expected. The frequency of rainfall occurrence is approximately $2 \%$ at the center grid box. The numbers of 
rain samples over the grid box are only 2,5 , and 57 for 1 , 3 , and $16 \mathrm{yr}$, respectively (Fig. 2c). The small number of rain samples results in a discrete spatial pattern. The rainfall occurrence frequency is high in the northeastern part of this region; however, the concentric pattern of the number of rain samples becomes clear, reflecting this pattern for all samples as the sample size increases. Therefore, the long-term data accumulation allows us to produce an image of ultra-high-resolution geographic rainfall patterns that is clear and reflects accurate geolocation data and locally fixed rainfall features despite an imaging blur caused by its original sensor resolution of approximately $5 \mathrm{~km}$. Strictly speaking, navigation data entail uncertainty in the ephemeris and the spacecraft attitude (NASA 2008). Recently, for the level 1 data of version 8 , the geolocation of PR's instantaneous field of view was revised in particular for the preboost period. There is room for further development concerning the accuracy; however, this study focuses on the result that the bias of the geolocation data is likely negligible for the average of a number of independent samples (Takahashi and Oki 2010).

The number of samples for each $0.01^{\circ}$ grid box at $34^{\circ} \mathrm{N}$ or $34^{\circ} \mathrm{S}$ is approximately 5 times larger than that in the tropics $\left(10^{\circ} \mathrm{S}-10^{\circ} \mathrm{N}\right)$. The latitude bounds, $36.13^{\circ} \mathrm{S}$ and $36.13^{\circ} \mathrm{N}$, were chosen such that the outer edges have the lowest sampling in the central band (i.e., at the equator). The intrinsic approximately $5-\mathrm{km}$ resolution of the PR is already exhausted on the $0.01^{\circ}$ grid; therefore, a finer grid would yield no additional details.

In addition to the TRMM PR data, four gauge-based precipitation datasets are used: Global Precipitation Climatology Centre (GPCC) version 7 full reanalysis data at the $0.5^{\circ}$ scale (Schneider et al. 2015) for the 16-yr period from 1998 to 2013; $0.05^{\circ}$-scale APHRO_JP V1207 data, a product of the Asian Precipitation Highly Resolved Observational Data Integration Toward Evaluation of Water (APHRODITE) project from 1998 to 2013 (Kamiguchi et al. 2010; Yatagai et al. 2012); long-term mean data from WorldClim version global climate dataset developed at the 30 -arc-s scale for the global land area (Fick and Hijmans 2017; Hijmans et al. 2005); and $0.05^{\circ}$-scale Climate Hazards Group Infrared Precipitation with Station (CHIRPS) version 2.0 data (Funk et al. 2015a) from 1998 to 2013. GPCC and APHRO_JP data are used in section 3a to check the conventional representations of the rainfall concentration in specific areas of Asia. In section 3b, comparisons of finescale spatial rainfall gradients are made with WorldClim and CHIRPS, which incorporate infrared imagery with in situ observations to ensure high-resolution datasets over the global land area. WorldClim is selected as a well-known 1-km-scale dataset. CHIRPS uses geostationary satellite thermal infrared data calibrated with TRMM Multisatellite Precipitation Analysis-3B42 and gauge data. The $0.01^{\circ}$ averaged elevation data are obtained from the 30-s Shuttle Radar Topography Mission global bathymetry and elevation data at 30-arc-s resolution (SRTM30; Farr et al. 2007).

\section{Results}

\section{a. Kilometer-scale spatial variation of rainfall}

The spatial nonuniformity of rainfall is examined using the ultra-high-resolution dataset. Figure 3 shows rainfall around the Meghalaya Hills in northeast India during the period of 1998-2013. The south-facing slope, particularly near the Cherrapunji valley, is known to be the wettest region in the world (WMO 2009). At the $0.5^{\circ}$ scale, the local maximum from TRMM PR data is $10.7 \mathrm{~mm} \mathrm{day}{ }^{-1}$. This value is considerably lower than that of conventional rainfall datasets such as GPCC $\left(19.8 \mathrm{~mm} \mathrm{day}^{-1}\right)$. At the $0.1^{\circ}$ scale, the rainfall peak at Cherrapunji reaches $19.4 \mathrm{~mm} \mathrm{day}^{-1}$ (Fig. 3b). The revised maximum at the $0.01^{\circ}$ scale (Figs. 3c,e; PR-A) is $28.9 \mathrm{~mm} \mathrm{day}^{-1}, 49 \%$ greater than the value at $0.1^{\circ}$. Figures $3 \mathrm{~d}$ and $3 \mathrm{f}$ indicate the $0.01^{\circ}$-scale rainfall but are based on the conventional approach of integrating data into the footprint center point of the grid coordinates (PR-B), which shows an extraordinarily high fluctuation arising from sparse temporal sampling. Therefore, the spatial mismatch in the data allocation leads to different patterns with extreme outliers; the same method can be applied to the conventional datasets at the $0.05^{\circ}$ scale, as shown later.

Figure $3 \mathrm{e}$ demonstrates that high-resolution data can resolve the local concentrations of rainfall induced by specific orography. The rain gauge at the western hill side $\left(25.25^{\circ} \mathrm{N}, 91.73^{\circ} \mathrm{E}, 1300 \mathrm{~m} \mathrm{MSL}\right)$ is located at a suitable site for the detection of extreme values (Prokop and Walanus 2015); however, in this study, the rainfall peak at the $0.01^{\circ}$ scale is found on the lower valley side $\left(25.245^{\circ} \mathrm{N}, 91.775^{\circ} \mathrm{E}\right)$, approximately $5 \mathrm{~km}$ east of the gauge station. The secondary maximum of $23.9 \mathrm{~mm} \mathrm{day}^{-1}$ appears in the adjacent valley of Mawsynram, approximately $10 \mathrm{~km}$ west of Cherrapunji. In addition to the steep spatial gradient of the rainfall, the year-to-year variation and its effect on the long-term mean are significant in these areas (Murata et al. 2008). For example, the maximum 13-yr mean rainfall (1998-2010) is located in the same grid box; however, its amount differs considerably from that of the $16-\mathrm{yr}$ data (by $16 \%$ ). This result indicates the importance of continued and enhanced observations in this area. 

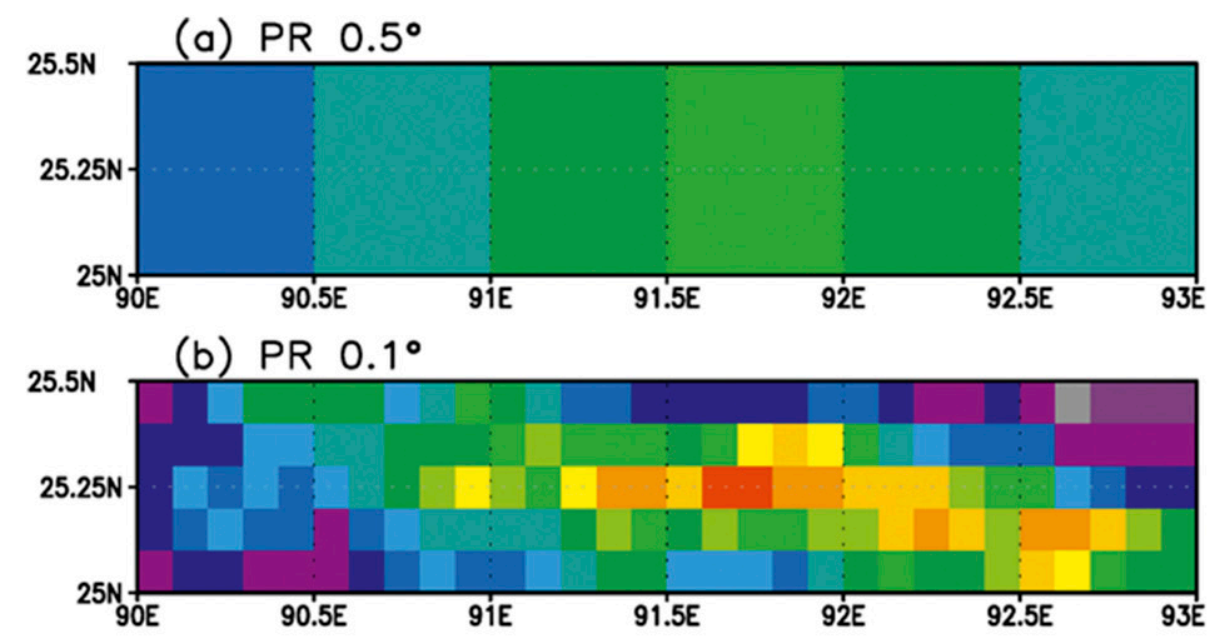

(c) PR-A $0.01^{\circ}$
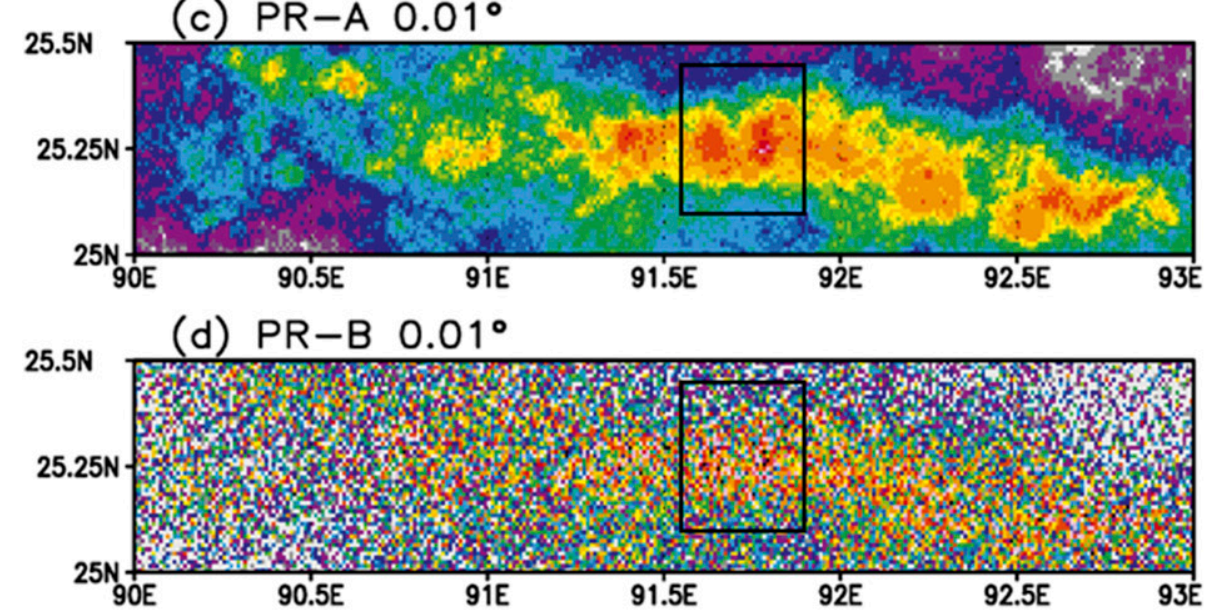

(e) PR-A $0.01^{\circ}$

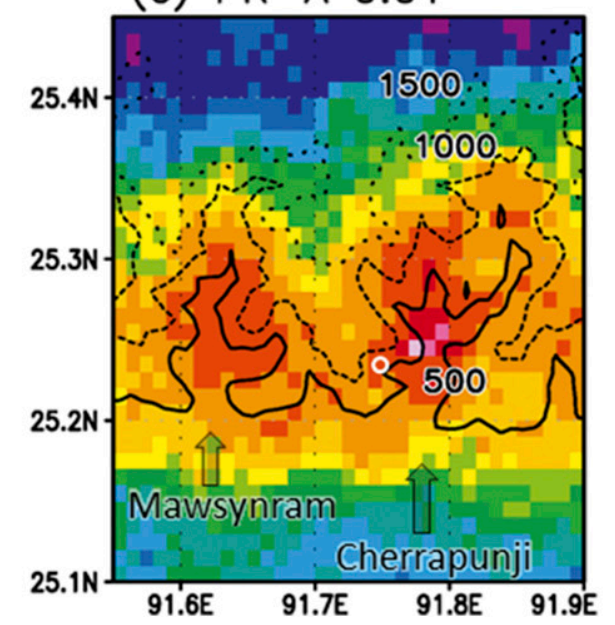

(f) $P R-B \quad 0.01^{\circ}$
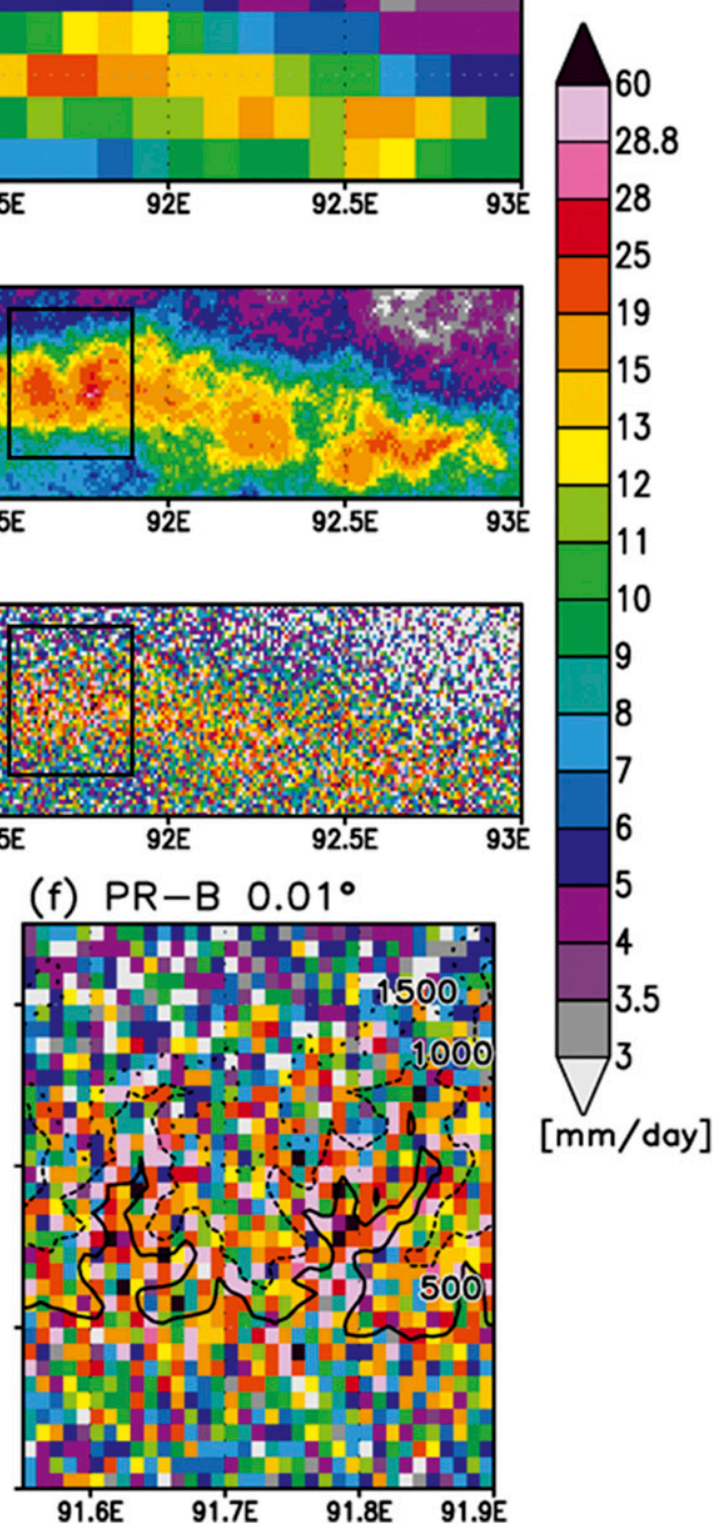

FIG. 3. Rainfall around the Indian state of Meghalaya: (a) $0.5^{\circ}$, (b) $0.1^{\circ}$, and $0.01^{\circ}$ scales from $16 \mathrm{yr}$ of TRMM PR data. Values for (c) PR-A and (d) PR-B are generated based on our subfootprint sampling approach and the conventional method, respectively. (e),(f) Enlarged maps of the rainfall around Cherrapunji at the $0.01^{\circ}$ scale; the contours indicate the altitude $(\mathrm{m})$. The rectangles inside (c) and (d) indicate the area analyzed in (e) and (f), respectively. The white circle in (e) indicates the location of the Cherrapunji observatory. 
(a)

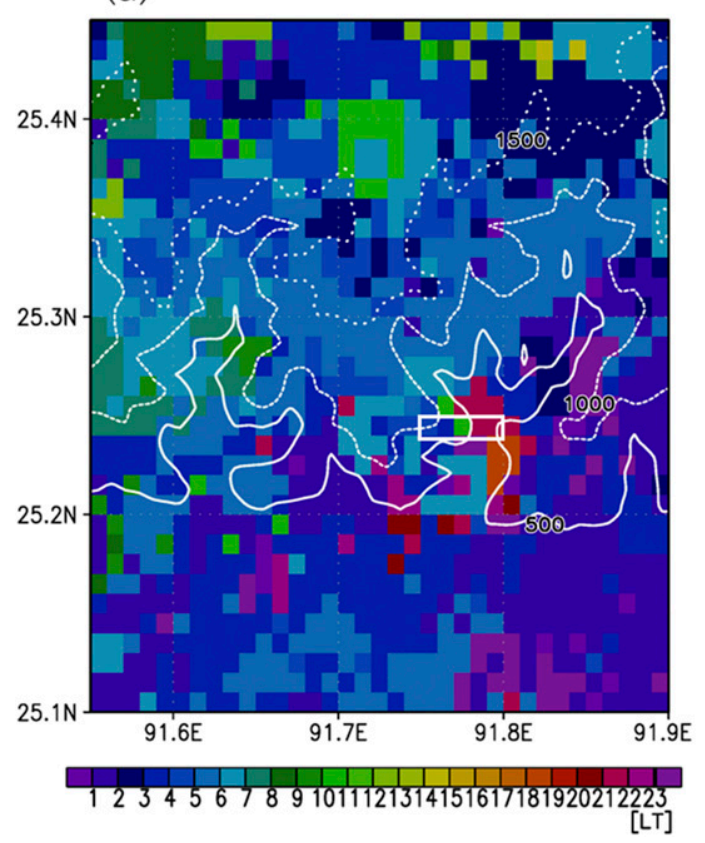

(b)

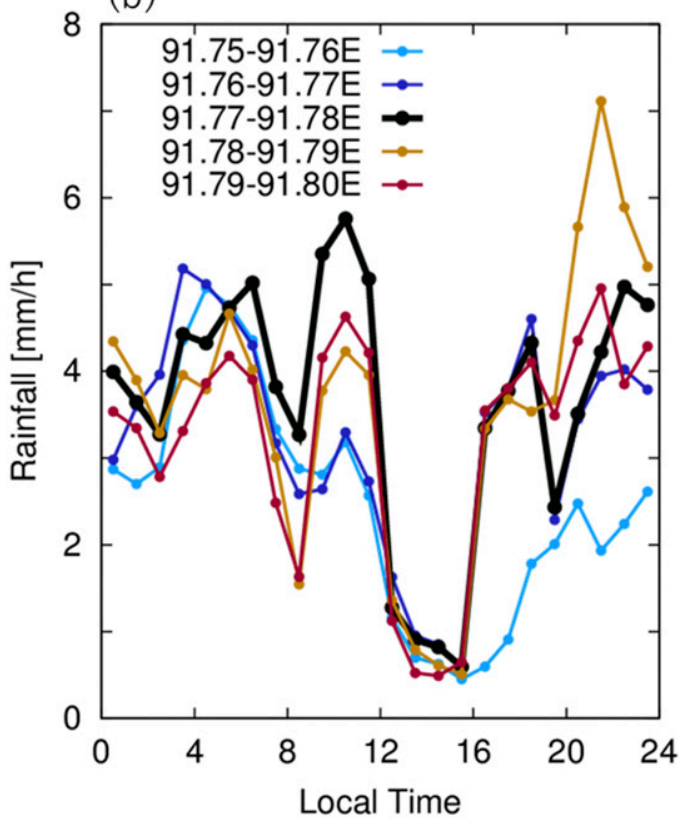

FIG. 4. (a) Time of maximum PR-A rainfall around the Cherrapunji valley at each $0.01^{\circ}$ grid. The area and topographic contours are the same as in Fig. 3. (b) Diurnal variation in the rainfall amount around the Cherrapunji valley. The time series of averages are plotted for five $0.01^{\circ}$ grid boxes across $25.24^{\circ}-25.25^{\circ} \mathrm{N}$, outlined by the rectangular area plotted in (a).

Figure 4 shows the diurnal variation in the PR-A rainfall around the Meghalaya Hills based on hourly data averaged with \pm 1 -h data. The rainfall maxima in the morning are conspicuous in being consistent with precedent studies (Fujinami et al. 2017; Terao et al. 2006). In the $0.01^{\circ}$ rainfall map, the time of maximum rainfall is observed in the morning but differs slightly by region (Fig. 4a). Over the grid box with maximum rainfall at the Cherrapunji valley, at the center of the white rectangular box $\left(25.24^{\circ}-25.25^{\circ} \mathrm{N}, 91.75^{\circ}-91.80^{\circ} \mathrm{E}\right)$ in Fig. 4a, the rainfall around $1000 \mathrm{LT}$ increases the total amount there in comparison with that over the western hillside, which has a peak near dawn. At the eastern lower valley side, the rainfall around 2200 LT prevails. Nighttime peaks only appear over the low-elevation areas. The difference in the time of maximum rainfall for 1998-2005 and that for 2006-13 was also examined (not shown). The localized rainfall around $1000 \mathrm{LT}$ at the hill does not prevail in the latter period; however, early morning peaks over most of the region and nighttime peaks over the low-elevation areas are observed for both periods. Therefore, the dataset offers an opportunity to resolve local climatology associated with kilometer-scale geography and to discuss the differences between satellite and ground observations (e.g., Terao et al. 2017). Given the significant diurnal variation shown in Fig. 4b, it is clear that the rainfall hot spot does not result from ground clutter interference, which should appear regardless of time.

Figure 5 shows the four types of rainfall climatology over Yakushima Island, Japan, which is known to be one of the most plentiful rainfall regions and is a world natural heritage site. The chosen site is a region with a large amount of orographic rainfall and a dense local gauge network. The TRMM PR rainfall climatology data are prepared with spatial resolutions of $0.1^{\circ}, 0.05^{\circ}$, and $0.01^{\circ}$. The PR-A in Fig. 5a and PR-B in Fig. 5c are based on our new dataset and a conventional dataset archived for each footprint center, respectively. The PR-B rainfall patterns at the $0.1^{\circ}$ and $0.05^{\circ}$ scales are slightly different from the corresponding PR-A rainfall patterns. The rainfall maxima are located in the same grid box; however, the PR-B peak values at the $0.1^{\circ}$ and $0.05^{\circ}$ scales are $0.7 \%$ greater and $8 \%$ less than those of PR-A, respectively. The difference in the conventional $0.05^{\circ}$-scale rainfall data, resulting from the sampling mismatch between the footprint and the grid box, should be kept in mind. Furthermore, significant differences appear for the $0.01^{\circ}$-scale climatology (Fig. 3). PR-B-type data (i.e., generated without considering the spatial extent of a footprint) lack values for the subfootprint statistics even for the decadal data accumulation. 
(a) $P R-A$

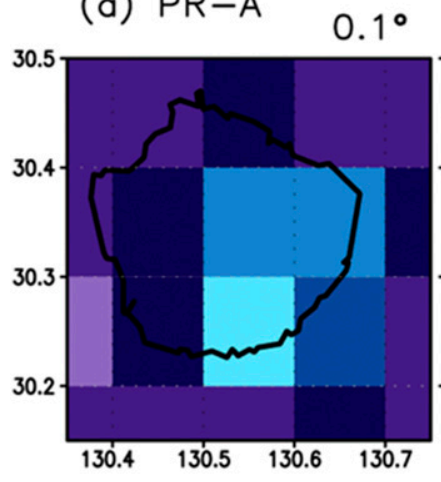

(c) PR-B

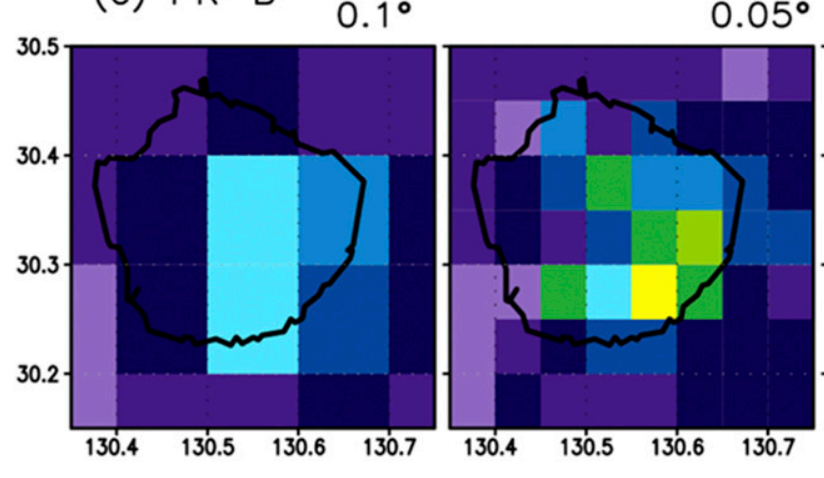

$0.05^{\circ}$
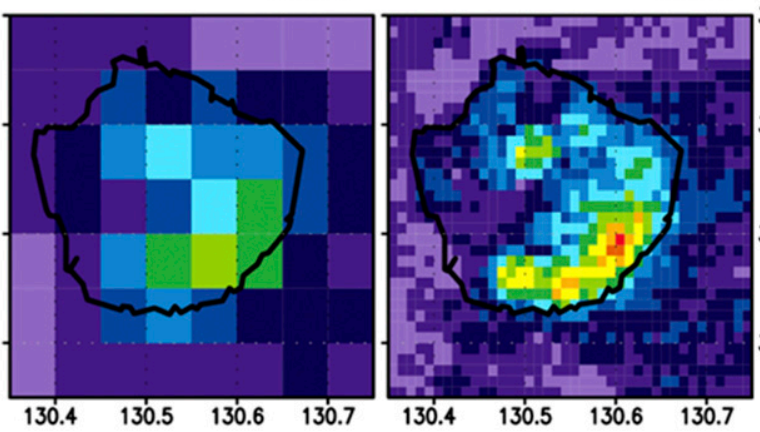

$0.01^{\circ}$

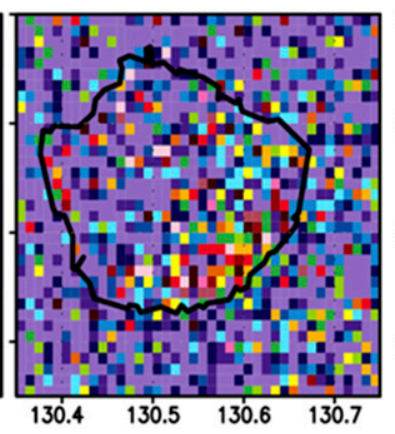

(b) Aphro_JP

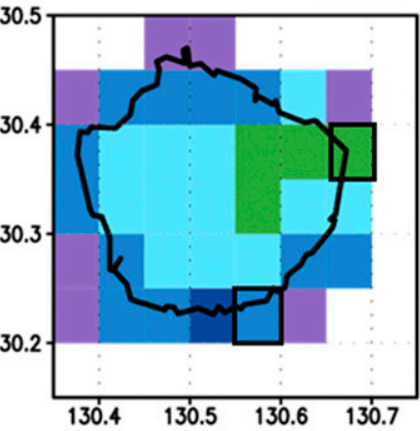

(d) Gauge
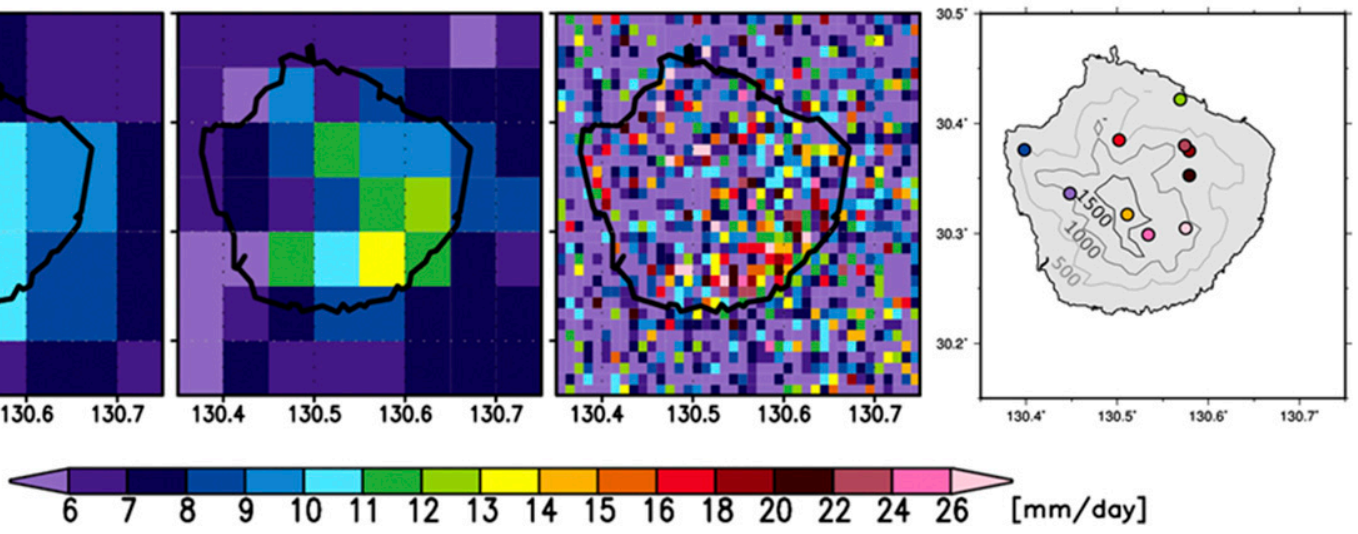

FIG. 5. Rainfall over Yakushima Island from 1998 to 2013: (a) PR-A at the $0.1^{\circ}, 0.05^{\circ}$, and $0.01^{\circ}$ scales; (b) rainfall at the $0.05^{\circ}$ scale from APHRO_JP; (c) PR-B at the same scales as in (a); and (d) in situ rainfall data. The solid squares in (b) indicate grid boxes with an observation site in the APHRO_JP data. Contours in (d) show the altitude (m).

For PR-A at the $0.1^{\circ}$ and $0.01^{\circ}$ scales, abundant rainfall is concentrated in the southern and southeastern regions, respectively, with peak values of 10.5 and $16.2 \mathrm{~mm} \mathrm{day}^{-1}$, respectively. For the $0.05^{\circ}$-grid scale, a peak of $12.9 \mathrm{~mm}$ day $^{-1}$ appears in the southeastern region; however, the grid box does not overlap with the $0.01^{\circ}$-grid peak location because there is a rapid dropoff in the PR to the east and southeast as depicted on the $0.01^{\circ}$ map. The inland peak in the southeastern region may result from heavy-rainfall events (Takahara and Matsumoto 2002). An evaluation of such local geographic associations should be conducted with the kilometer-scale data. These rainfall maxima locations are different from those based on the gauge-based dataset because of the insufficient spatial representation of the station data. For example, APHRO_JP data yield a $0.05^{\circ}$-scale rainfall maximum of $11.8 \mathrm{~mm}^{-}$day $^{-1}$ in the northeast of this region (top box in Fig. 5b), which lies on the windward side of the central mountain (1936 m MSL). The APHRO_JP dataset incorporates observation data from the Automated Meteorological
Data Acquisition System. The number of gauges used in APHRO_JP is plentiful but includes only two for this island (boxes in Fig. 5b). Figure 5d shows the long-term average based on offline station data archived by the Kyusyu regional forest office. The peak rainfall appears in the southeastern region; however, the spatial pattern does not sufficiently match the satellite data. The maximum rainfall is $27.4 \mathrm{~mm}_{\text {day }}{ }^{-1}, 1.7$ times greater than the $0.01^{\circ}$ scale TRMM PR rainfall maximum. In this case, the satellite observation indicates the importance of sharpened data, an improved understanding of retrieval and sampling uncertainties in the gauge-based dataset, and the further clarification of satellite retrieval uncertainties. Even though the regional differences in the rainfall between the APHRO_JP and TRMM PR data are unclear with respect to the presence or absence of gauges, our preliminary examination shows that the rainfall discrepancies between GPCC and TRMM PR are smaller over areas with gauges than over areas without gauges (not shown). Uncertainties in the finescale orographic rainfall estimates from gauges are further described in the next section. 
The differences between the rainfall data at resolutions of $0.1^{\circ}$ and $0.01^{\circ}$ are significant in mountainous areas, as indicated by Figs. 3 and 5. The number of grid boxes in which the difference is greater than $10 \mathrm{~mm}_{\text {day }}{ }^{-1}$ is $1970\left(2284 \mathrm{~km}^{2}\right)$ over the entire domain. Of the significantly different grid boxes, $86 \%$ appear over steep slope areas with spatial elevation gradients $>10 \%$, which correspond to $7.7 \%$ of the land area $\left(36.13^{\circ} \mathrm{S}-36.13^{\circ} \mathrm{N}\right)$. Of areas with a spatial gradient $>50 \%, 0.3 \%$ of the grid boxes have significantly different rainfall values between the $0.1^{\circ}$ and $0.01^{\circ}$ scales; this occurrence frequency is approximately 10 times greater than that for areas with a spatial gradient $>10 \%$. Significant differences in rainfall $\left(>10 \mathrm{~mm}\right.$ day $\left.^{-1}\right)$ seldom occur over flat land (only five grid boxes). The spatial variation in the mean rainfall by grid scale is examined in terms of the coefficient of variation $(\mathrm{CV})$ for the $0.01^{\circ}$ rainfall at a $0.1^{\circ}$ scale over Asia (Fig. 6). The $\mathrm{CV}$ is defined as the standard deviation of the $0.01^{\circ}$ rainfall divided by the average for each $0.1^{\circ}$ grid box. The $\mathrm{CV}$ shows the spatial nonuniformity of the rainfall and highlights the sampling uncertainty as well as retrieval issues over specific regions, as discussed later. The highest and lowest CV values are observed over the Tibetan Plateau and areas east of Japan, respectively, even though most of these areas are masked because of the small differences in the rainfall at the different resolutions. Over the Tibetan Plateau, where the amount of rainfall is small, the CV is high, indicating that small-scale regional circulation is predominant in this area. This finding is consistent with previous studies that showed a high fraction of smallscale convection and relatively few large-scale disturbances (Hirose et al. 2009). High CV values are also observed over slope areas with high spatial rainfall gradients, such as the Himalayas and the Western Ghats. On the coastal side of the Western Ghats, the significant impact of widespread systems results in low CV values. These geographically fixed variations in the CV demonstrate the benefits of ultra-high-resolution data in revealing the spatial representation of orographic influences. Over the ocean to the east of Japan, where the $\mathrm{CV}$ is lowest, both the rainfall amount and the number of satellite overpasses are high. The small difference in the rainfall at different resolutions is attributable to the significant effect of abundantly sampled, widespread systems in the midlatitudes (Hirose et al. 2017a). Over other oceans, particularly in rainy areas, spatially homogeneous rain patterns result in low $\mathrm{CV}$ values, and the $\mathrm{CV}$ is ultimately reduced to near zero at these locations. Over waters with low-rainfall amounts, sparse sampling of large systems and the relatively high fraction of small systems result in relatively high $\mathrm{CV}$ values. In such regions, the advantages of the $0.01^{\circ}$-rainfall

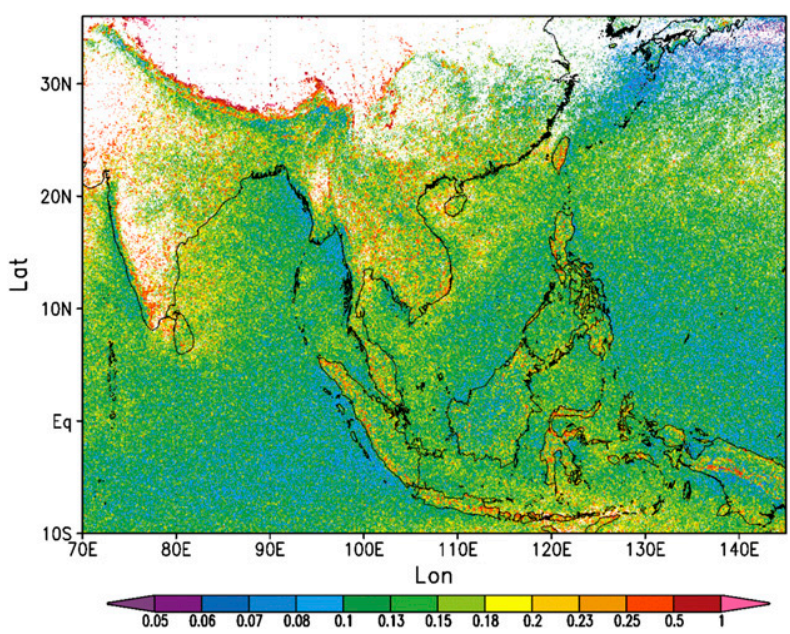

FIG. 6. The CV values for $0.01^{\circ} \mathrm{PR}-\mathrm{A}$ rainfall at the $0.1^{\circ}$ scale over Asia. The area where the difference in rainfall between the $0.01^{\circ}$ and $0.1^{\circ}$ scales is $<0.1 \mathrm{~mm} \mathrm{day}^{-1}$ is blanked out.

climatology are less significant; however, finescale observations are necessary to detect the prevailing smallscale and shallow convection.

In addition to the topographically affected localized rainfall, the discrepancies at different resolutions reveal the geographical background of retrieval issues in mountainous regions. For example, several highly specific values greater than $20 \mathrm{~mm}_{\text {day }}{ }^{-1}$ are scattered over specific areas in the Karakoram region. These appear as spatially fixed point-like signals on the steep terrain. They are difficult to discern on the coarse global map but are revealed by certain orographic rainfall statistics. Figure 7 illustrates the $0.01^{\circ} \mathrm{PR}-\mathrm{A}$ rainfall and $\mathrm{CV}$ averaged by elevation over land. For all land areas in the region of $36.13^{\circ} \mathrm{S}-36.13^{\circ} \mathrm{N}$, the rainfall averaged using a $10-\mathrm{m}$ elevation increment has a maximum of $3.39 \mathrm{~mm} \mathrm{day}^{-1}$ at $10-20-\mathrm{m}$ elevation and decreases to $1.78 \mathrm{~mm} \mathrm{day}{ }^{-1}$ at $290-300 \mathrm{~m}$. The average rainfall is nearly constant for the medium-elevation areas (300$2800 \mathrm{~m}$ ) and then decreases monotonically according to elevation because of the low orographic convergence. However, extraordinarily high precipitation appears at high-altitude areas $(6000 \mathrm{~m})$, where the water vapor and precipitation amounts are generally low. Suspicious signals characterized by isolated extremely high precipitation appear to be more significant for finerelevation increments. Meanwhile, the CV value over flat land is 0.18 and increases to 0.32 at $580 \mathrm{~m}$. Similar to rainfall, significant fluctuations in the $\mathrm{CV}$ are observed over high-elevation areas $(>6000 \mathrm{~m})$. As noted previously, high CV values are observed over low-rainfall highlands, where local systems are predominant. However, the high $\mathrm{CV}$ values for the high rainfall in the alpine 


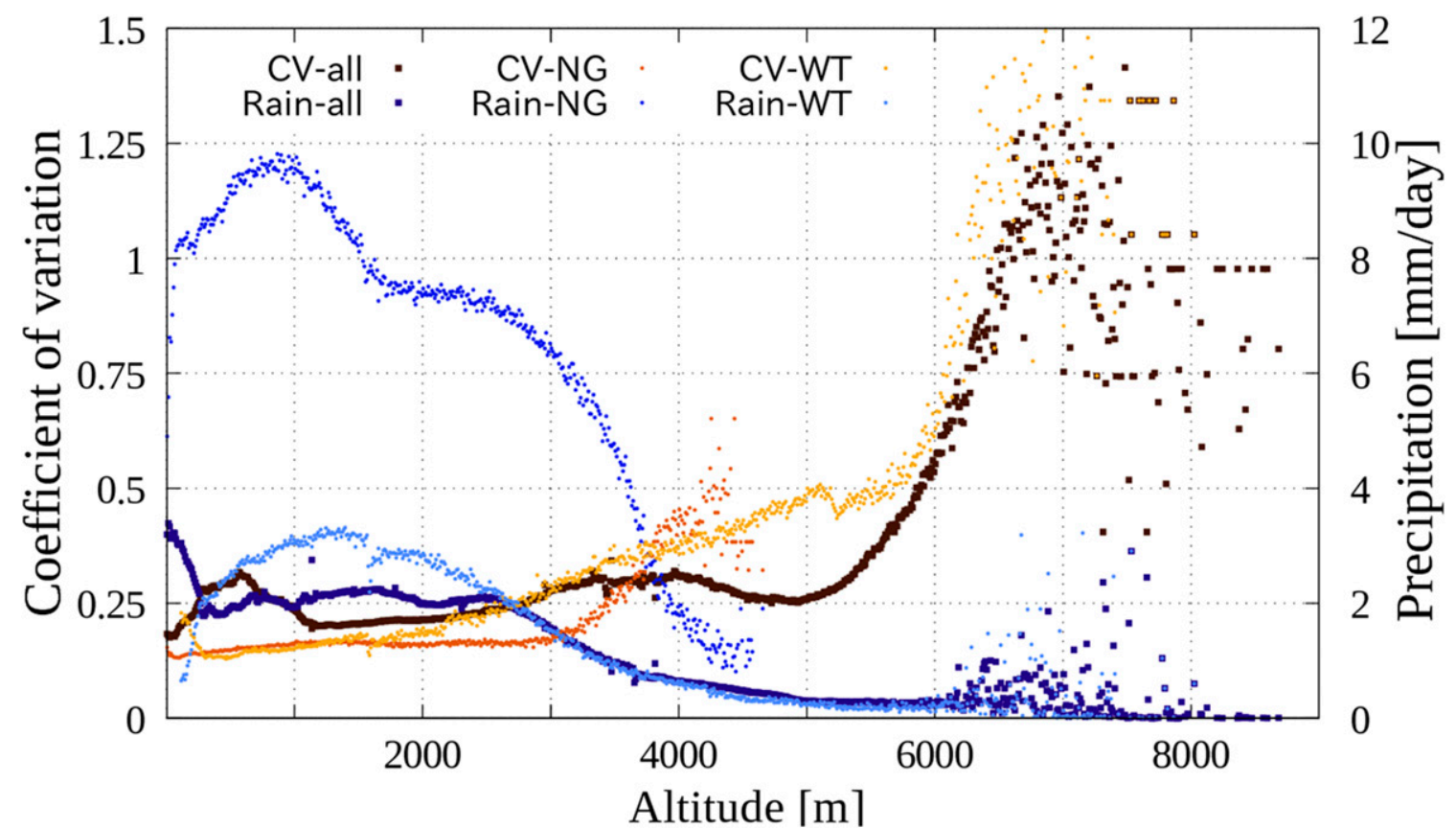

FIG. 7. PR-A rainfall (blue and purple) and CV (black and orange) for each 10-m elevation increment over land (all), NG, and WT.

areas seem likely to be incorrect. Figure 7 shows other examples of the elevation dependency of rainfall and $\mathrm{CV}$ over the island of New Guinea (NG; $10^{\circ} \mathrm{S}-0^{\circ}$ and $130^{\circ}-150^{\circ} \mathrm{E}$ ) and the western part of the Tibetan Plateau (WT; $30^{\circ}-36.13^{\circ} \mathrm{N}$ and $70^{\circ}-80^{\circ} \mathrm{E}$ ). The rainfall has a maximum at slope areas where moisture convergence is evident. The cases for NG and WT display rainfall peaks near 1 and $1.3 \mathrm{~km}$ in altitude, respectively. The CV value for $\mathrm{NG}$ increases at elevations higher than $3 \mathrm{~km}$ in accordance with the decreasing rainfall there. Conversely, the CV value for WT gradually increases with elevation until $6 \mathrm{~km}$. At levels higher than $6 \mathrm{~km}$, near the Karakoram region around $35^{\circ}-36^{\circ} \mathrm{N}$, extremely high CV values are observed with abnormally high rainfall signals at specific areas.

Ultra-high-resolution information can help us recognize artificial signals such as point-like extraordinarily intense values on steep terrain (e.g., a small region of the Himalayas as mentioned above or a high mountain on Réunion Island). The most extreme example is an anomalous point value $\left(>180 \mathrm{~mm} \mathrm{day}^{-1}\right)$ in the western region of Alejandro Selkirk Island, Chile (Fig. 8a). The extreme value in this low-rainfall area is highest for the $0.1^{\circ}$ and $0.01^{\circ}$ scales. Such point signals are observed regardless of the observation patterns and periods. Given that the lowest levels of surface echoes on steep terrain are partially lower than the elevation from SRTM30 in the current version 7 product, they are likely attributable to clutter contamination resulting from insufficient elevation data or nonuniformity (Hamada and Takayabu 2014; Duan et al. 2015). The impact of clutter contamination is inconspicuous in most cases; however, attention should be paid to specific orographic rainfall statistics (e.g., the maximum value over alpine areas) (Hirose et al. 2017a,b).

Figure $8 \mathrm{~b}$ shows another example of an artificial signal found in the $0.01^{\circ}$-scale rain climatology. The abovementioned intense clutter-related signals appear near rugged surfaces. However, this type of weak point-like signal is even detected over flat land; it is characterized by constant radar reflectivity close to the noise level for the entire vertical range (not shown). This results from a deficiency in the algorithm for the removal of artificial noise from the ground. It has been confirmed that the system noise warning flag defined in the 1B21 algorithm has not worked adequately since 2001 (T. Kubota 2015, personal communication). Therefore, understanding finescale spatial features is also useful for detecting artificial signals from surface and human activities. In other words, discussions of the high-resolution precipitation climatology increase the need for better artifact controls.

\section{b. Comparison of the spatial gradients of rainfall}

The differences in coarse-scale or point-like rainfall estimates between TRMM PR and other datasets have been discussed in a number of studies. Hirose et al. (2017b) showed that TRMM PR has advantages in the detection of 
(a)

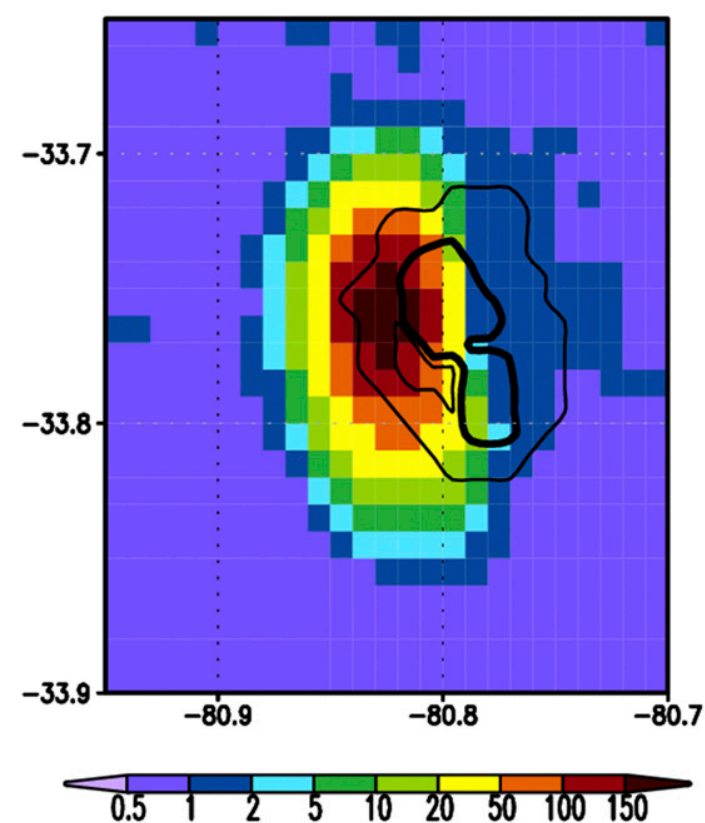

(b)

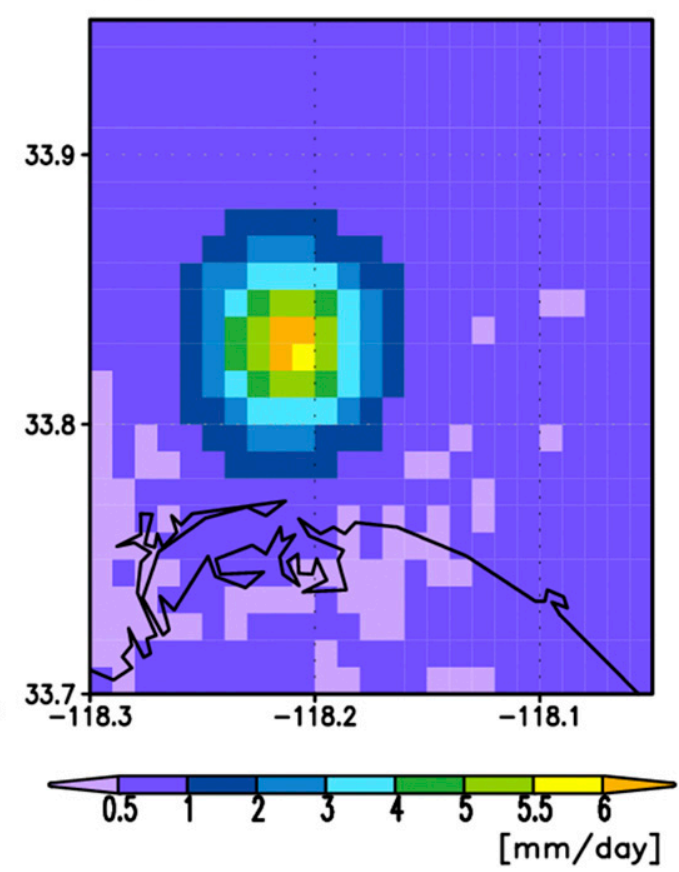

FIG. 8. Rough estimates of PR-A rainfall (a) over Alejandro Selkirk Island and (b) near Long Beach, California. The thicker line in (a) indicates an altitude of $500 \mathrm{~m}$ (from SRTM30).

orographic and coastal rainfall at the $0.1^{\circ}$ scale. This section examines differences in the fine rainfall climatology between our PR-A dataset and the gauge-based products WorldClim and CHIRPS to evaluate the performance of spaceborne radar data in comparison with other highresolution data for land areas.

Figure 9 shows the differences and anomalies between the TRMM PR and WorldClim rainfall data at the $0.01^{\circ}$ scale over Asia and the western region of South America, where the geographically induced rainfall and differences are conspicuous. TRMM PR rainfall is low overall relative to WorldClim rainfall, a finding that is similar to previous validation results (e.g., Prat and Barros 2010; Chen et al. 2013; Terao et al. 2017). This study focuses on the distinct regional differences highlighted by this dataset. Areas of significantly low rainfall appear over the highest range of New Guinea, the northern region of the Meghalaya Plateau, and the western coasts of India, Myanmar, and Colombia. TRMM PR rainfall is relatively low over cool and dry regions such as the Tibetan Plateau and the western coast of Chile (Figs. 9c,d). The TRMM PR rain climatology database at the $0.01^{\circ}$ scale has a high detection ability for dry spots even though the retrieval error possibly increases over steep terrains because of the thick layer caused by surface clutter and its insufficient sensitivity to snowfall (e.g., Duan et al. 2015; Schauwecker et al. 2016). The blur remains a problem; however, the nonuniform beam filling (NUBF) effect on the PIA estimate is considered to be insignificant for weak precipitation at high-altitude areas (Kirstetter et al. 2015). Conversely, TRMM PR rainfall is considerably higher than WorldClim rainfall on the mountainous slopes of New Guinea. In comparison with WorldClim, the difference is approximately $10 \mathrm{~mm}$ day $^{-1}$ and the anomaly is $100 \%$. The concentration of TRMM PR rainfall over the narrow slope areas in Sumatra and the Andes is also significant. In the Thar Desert of western India, the TRMM PR rainfall is greater than the gauge dataset. The difference is negligible (as shown in Fig. 9a); however, the ratio is significant over such hot and dry regions. Another example for a dry region is found in the western region of the Tibetan Plateau, where the TRMM PR rainfall is higher than that of WorldClim V2.0 but lower than that of the previous WorldClim V1.4 (not shown). In comparison with V1.4, more than $50 \%$ of the WorldClim V2.0 rainfall amounts are reduced over western Tibet, which seems to be due to the effect of the MODIS cloud cover constraints used in the updated WorldClim algorithm.

The TRMM PR rainfall shows considerable underestimations for wide areas, systematic regional differences in low-rainfall areas, and a sharp spatial gradient of orographic rainfall as compared with the WorldClim rainfall. These differences are also found for the gauge 
(a)

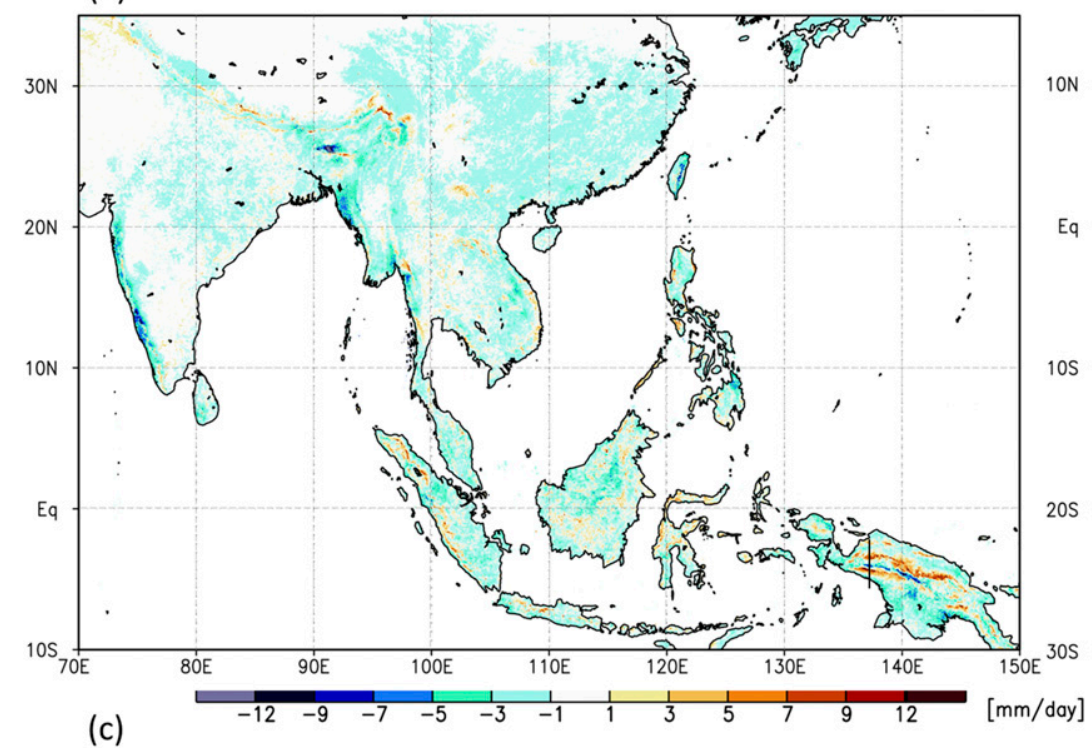

(c)

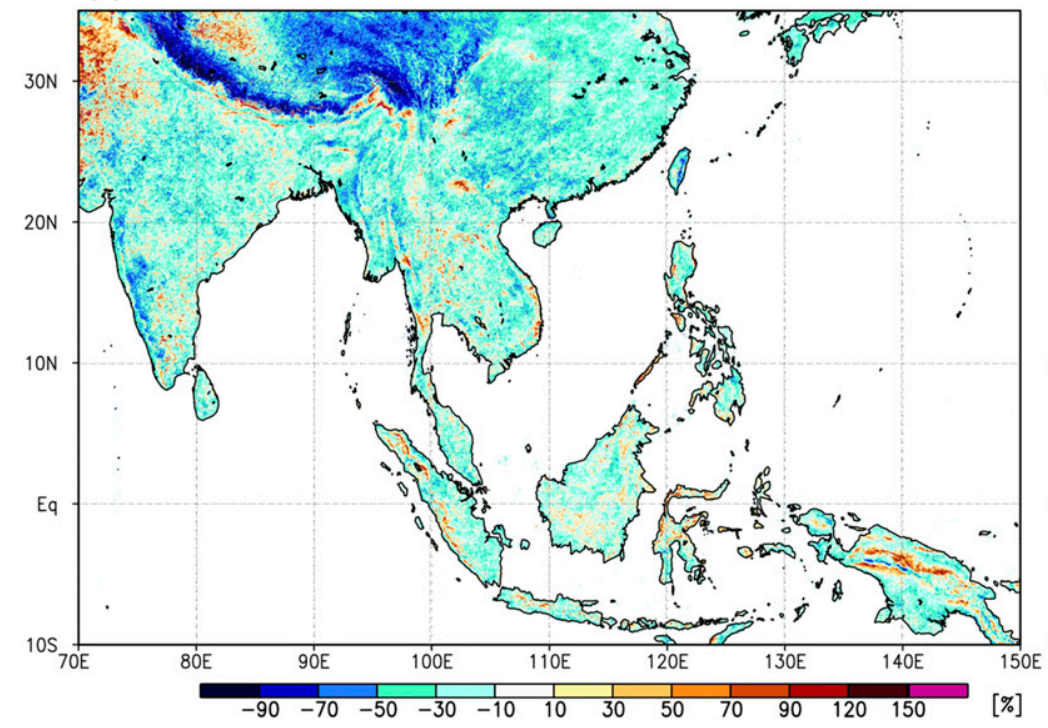

(b)

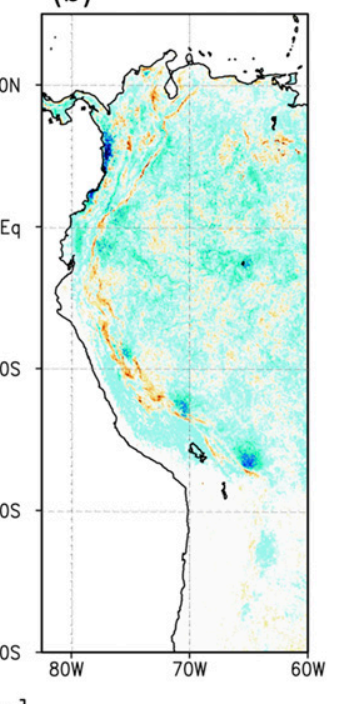

(d)

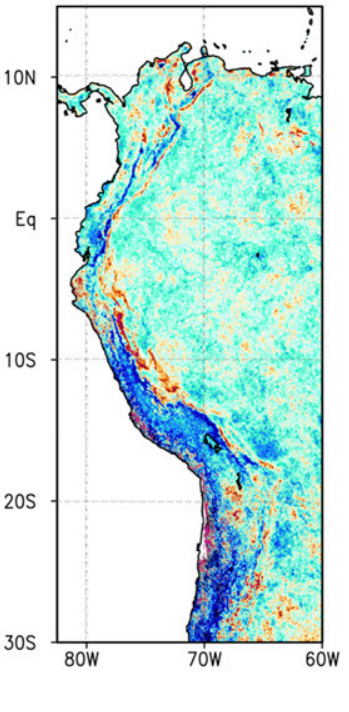

FIG. 9. Comparison of the (top) differences and (bottom) anomalies between the PR-A and WorldClim $0.01^{\circ}$ rainfall climatologies over (a),(c) Asia and (b),(d) western South America. The line over New Guinea in (a) locates the cross section depicted in Fig. 11, below.

product CHIRPS (Fig. 10). This comparison is performed for the $0.01^{\circ}$ grid to assess local differences in highresolution data, even though CHIRPS was originally generated at the $0.05^{\circ}$ scale. Over the southern region of the Tibetan Plateau, just behind the Himalayas, the CHIRPS rainfall is more than twice that of TRMM PR. Further studies should mitigate the large-scale bias. Conversely, a clear zonal contrast emerges between the rainfall concentration over the windward slope of the Western Ghats in the western region of India and its adjacent rain shadow (Figs. 10a,c). The difference relative to TRMM PR is less than that for WorldClim and is small for the coarse-scale average. This difference is due to the product resolution and the rainfall distribution of the local concentration on the western slope and the rain shadow on the leeward side (Hirose et al. 2017b). The difference between TRMM PR and CHIRPS is smaller in this region. On the ridge of the tropical Andes, the rainfall given by TRMM PR is considerably less than that given by CHIRPS and WorldClim. Such an identification of dry regions resolved by the finescale TRMM PR data sheds light on 
(a)

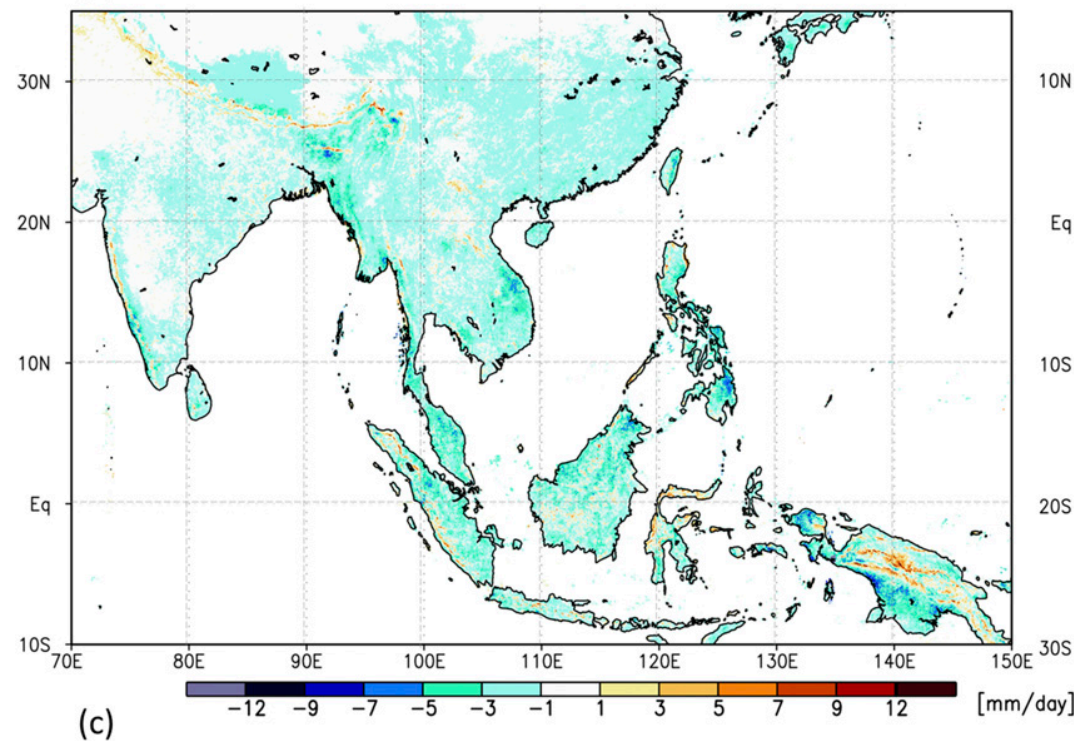

(c)

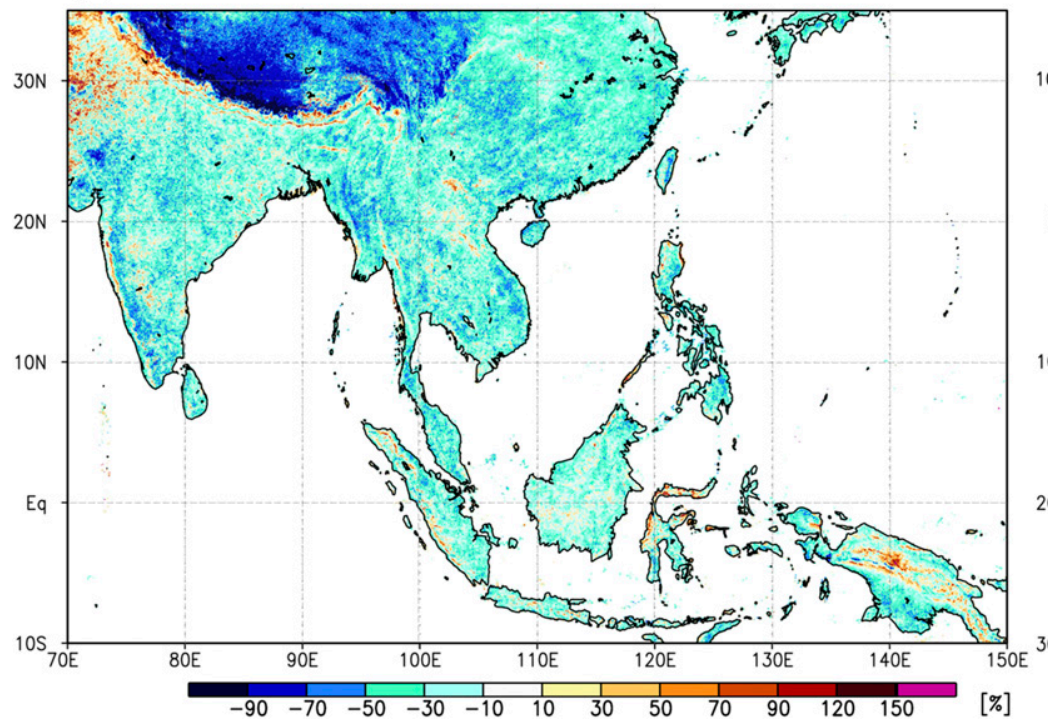

(b)

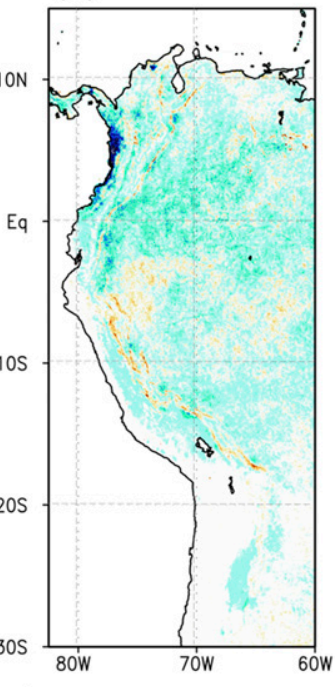

(d)

FIG. 10. As in Fig. 9, but using CHIRPS as the reference instead of WorldClim.

two issues. One is the difficulty in detecting snowfall near the surface, as discussed later. The other is the underlying issue of the use of high-resolution gaugebased products at the tops of mountain ridges.

One of the largest differences between the TRMM PR and gauge products is found over the island of New Guinea. Figure 11 focuses on the meridional rainfall variation to examine the sharp spatial gradients in rainfall over gauge-sparse regions. The TRMM PR rainfall at the $0.01^{\circ}$ scale shows a local concentration on the slopes and a considerable decline near the summit of the highest mountain of Oceania, Puncak Jaya (Fig. 11d). The WorldClim rainfall, characterized by elevation and
MODIS cloud cover, does not depict a significant gradient in this area (Fig. 11b). WorldClim V2.0 mitigates this elevation deficiency to some extent. Nevertheless, it clearly requires further constraints to represent kilometer-scale rainfall gradients over such ungauged orographic areas. WorldClim V2.0 uses MODIS data, operated in a sun-synchronous orbit, which would miss evening rainfall on the slope and nighttime rainfall over the foothills (Fig. 11e). Conversely, CHIRPS resolves the bimodal variation by incorporating infrared radiometer data from geostationary satellites (Fig. 11c). However, the peaks are shifted to the low-altitude areas and reach only approximately half of the corresponding $0.01^{\circ}$-scale 

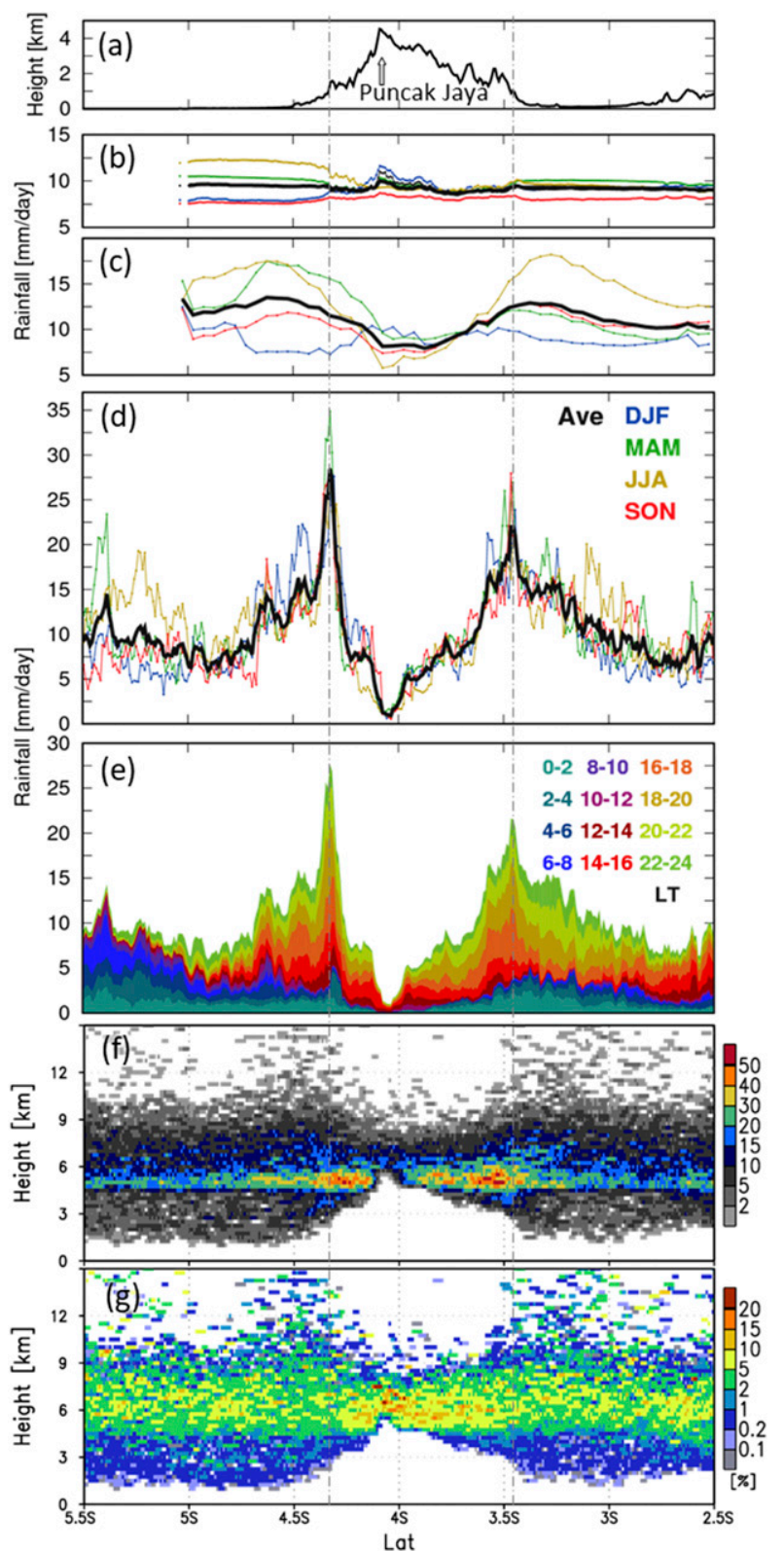

FIG. 11. Latitudinal cross section of the rainfall across Puncak Jaya, New Guinea, at $137^{\circ} 11^{\prime} \mathrm{E}$ : (a) altitude by 30 -s SRTM30, (b) seasonal rainfall by 30 -s WorldClim V2.0, (c) seasonal rainfall by $0.05^{\circ}$-scale CHIRPS V2.0, (d) seasonal rainfall by $0.01^{\circ}$-scale PR-A, (e) diurnal composition of the annual PR-A rainfall, (f) number of storm-top heights observed by TRMM PR, and (g) contribution to the surface rainfall by storms in various storm-top height classes. The thick black lines in (b) and (c) indicate the annual average; the thin black line in (b) represents the same but for WorldClim V1.4. The PR-A seasonal color legend in (d) also applies to (b) and (c). The dot-dash vertical lines in each panel indicate the latitudes of the peaks in PR-A.

PR rainfall. The IR-based diurnal timing is generally late by a few hours, reflecting different stages in the evolution of convective precipitation over land (Yamamoto et al. 2008). This sensor signature could be one reason for the difference in the peak rainfall between TRMM PR and CHIRPS. The sampling uncertainty is increased in the seasonal TRMM PR product; therefore, spatial features should be considered to describe the systematic differences. Nevertheless, significant differences between the products can be seen, particularly in winter. Peaks on slopes where the gradient slightly increases are observed throughout the year (Fig. 11d). This is not attributable to ground clutter contamination in view of the vertical structures, as explained below.

Figure 11f shows a histogram of the echo-top height, which is the top of the three consecutive range bins filled with meaningful echoes. The vertical resolution is $250 \mathrm{~m}$. The greatest number of storm-top heights is concentrated near an altitude of $5 \mathrm{~km}$, particularly on slope areas. Concentrations of echo-top heights near the freezing layer in the tropics are widely observed over tropical land areas (Chen and Fu 2018). Over mountain ridges, storms with top heights $<6 \mathrm{~km}$ are not detected. Deeper storms composed of ice are homogeneously observed regardless of the geography; however, very deep storms higher than $10 \mathrm{~km}$ rarely appear over ridges. In addition to the interpolation uncertainty over ungauged areas (an issue for WorldClim, CHIRPS, and GPCC), the detectability of light precipitation by TRMM PR needs to be further evaluated using accumulated Global Precipitation Measurement (GPM) Dual-Frequency Precipitation Radar (DPR) data and in situ observations. Figure $11 \mathrm{~g}$ shows the fraction of surface rainfall for different ranges of storm-top height. In general, deep storms correspond to high rainfall rates at the surface except for extreme cases (Hamada et al. 2015). Therefore, only a few percent of the total rainfall results from several snapshots of deep storms, even over $16 \mathrm{yr}$. The number of shallow storms well below freezing levels increases over slope areas (Figs. 11f,g); however, there are no features indicating that the statistics of echoes trapped at the surface determine the local concentration near mountain ranges. This heightlatitudinal cross section indicates that localized peaks are attributable to rainfall events with a wide range of storm-top heights.

\section{Conclusions}

A very-finescale rainfall map was generated from $0.01^{\circ}$-scale rainfall data (PR-A) by carefully accounting for the footprint position on the analysis grid, making full use of the long-term TRMM PR observations. This study indicates that the effect of the surrounding pixels on the average for each $0.01^{\circ}$ grid box becomes less prominent as a longer record of data accumulation is achieved, even though the development of a 
narrow-beam radar (requiring a large antenna) is awaited to discern the true variability in the future. The new PR-A very-high-resolution dataset can be used to examine significant geographic associations of orographic rainfall. In total, $86 \%$ of grid boxes where the difference between the $0.1^{\circ}$ - and $0.01^{\circ}$-scale rainfall is greater than $10 \mathrm{~mm} \mathrm{day}^{-1}$ are concentrated in steep slope areas with spatial elevation gradients $>10 \%$. The results demonstrate the possibility of using spaceborne radar climatology to develop better regional representations based on station observations. The identification of local rainfall concentrations could result in discussions concerning observation site optimization and the spatiotemporal characteristics of the orographic effect to allow more accurate regional water information based on other observations and models (e.g., Alvarez et al. 2014; Sugimoto and Takahashi 2016). The TRMM PRderived diurnal modulation of the orographic precipitation property is useful for fully resolving regional storm spectra over ungauged areas. Nighttime rainfall peaks are observed at the bases of mountains near the Cherrapunji valley; this is distinct from early morning rainfall peaks observed in the surrounding regions. Such regional features with a spatial extent of several kilometers could be useful to better understand the link between satellite and ground observations. Highresolution PR-A rainfall data can resolve high rainfall on specific slope areas and low-rainfall areas along mountain ridges. The statistics on the vertical structure of rainfall also indicate a high contrast in the frequency of storm occurrence. Such information may prove useful in improving finescale highland climatologies based on gauge datasets, which need to be improved to understand regional climate change and application studies such as altitudinal biodiversity patterns (Mutke et al. 2014).

The comparison also showed systematic retrieval differences in rainfall climatology between spaceborne radar and in situ datasets. The homogenous pattern indicates that the finescale TRMM PR climatology is composed of a number of sufficient high-impact samples (Hirose et al. 2017a). An underestimation bias could result from several factors such as the NUBF effect on the attenuation correction, the impact of the main-lobe clutter filtering, and the lack of sensitivity to low rainfall (e.g., Kirstetter et al. 2013). The upcoming TRMM PR version 8 algorithm is expected to provide different biases by revising the calibration factor and the raintype classification. It is necessary to closely examine which factors determine the widespread bias. This study demonstrates that high-resolution PR-A data are useful for detecting retrieval uncertainties related to removing the main-lobe and radio interference artifacts. The former issue for the $2 \mathrm{~A} 25$ version 7 data has also been raised by Hamada and Takayabu (2014) and Duan et al. (2015). The latter issue should be adequately addressed within the context of the system noise limit in the 1B21 algorithm. Over alpine areas, further investigations are required to understand the rainfall nonuniformity due to the limited footprint resolution and partial clutter interference in addition to the detection ability of snowfall. Clutter contamination and the NUBF problem need to be mitigated by developing appropriate algorithms and improving sensor resolution in the future. The filtering of artificial noise from the ground is also necessary to assess point-like rain concentrations, particularly at high levels, over dry regions, and for studies on urban effects. Furthermore, data from the GPM Core Observatory will allow for the further refinement of precipitation climatology data. The geolocation data of the GPM Core Observatory are more accurate than the TRMM data, and the sensitivity and detectability for shallow storms have been improved (Hamada and Takayabu 2016). Recently, geolocation information of the version 8 TRMM $\mathrm{PR}$ product has been improved using the gyro data and PR roll information, which also need to be examined in the future. By understanding the mismatch between these observation products of the orographic rainfall behavior in the low atmosphere, the robustness and applicability of the geographic precipitation database will be enhanced. Further sensor response across the one-way 3-dB beamwidth and corrections regarding the nonuniform beam filling effect for each footprint remain challenging (e.g., Short et al. 2009).

To facilitate use of the PR-A precipitation climatology data based on $0.01^{\circ}$-rainfall information, we provide the ultra-high-resolution global rainfall data and digital maps on our website (https://www.rain-clim.com; Hirose 2018). Zooming in and changing the transparency of the map allow us to observe the distinct local precipitation climatology at various locations around the globe. A 3D view is also implemented to help understand the close relationship between topography and the corresponding surface rainfall.

Acknowledgments. The authors express their gratitude to the members of the TRMM and GPM projects. This study was mainly supported by the seventh and eighth GPM/TRMM research announcements of JAXA. The authors thank the data developers of the TRMM PR, APHRODITE, GPCC, WorldClim, and CHIRPS projects for producing and making available their precipitation datasets. They also thank Dr. F. Akimoto for providing the compilation of data used in this study. The authors thank Dr. Iguchi for his scientific comments and continuous encouragement. They are grateful for the constructive comments of the anonymous reviewers. 


\section{REFERENCES}

Alvarez, O., Q. Guo, R. C. Klinger, W. Li, and P. Doherty, 2014: Comparison of elevation and remote sensing derived products as auxiliary data for climate surface interpolation. Int J. Climatol., 34, 2258-2268, https://doi.org/10.1002/joc.3835.

Biasutti, M., S. E. Yuter, C. D. Burleyson, and A. H. Sobel, 2012: Very high resolution rainfall patterns measured by TRMM Precipitation Radar: Seasonal and diurnal cycles. Climate Dyn., 39, 239-258, https://doi.org/10.1007/s00382-011-1146-6.

Chen, S., and Coauthors, 2013: Evaluation of spatial errors of precipitation rates and types from TRMM spaceborne radar over the southern CONUS. J. Hydrometeor., 14, 1884-1896, https://doi.org/10.1175/JHM-D-13-027.1.

Chen, Y., and Y. Fu, 2018: Tropical echo-top height for precipitating clouds observed by multiple active instruments aboard satellites. Atmos. Res., 199, 54-61, https://doi.org/ 10.1016/j.atmosres.2017.08.008.

Daly, C., M. Halbleib, J. I. Smith, W. P. Gibson, M. K. Doggett, G. H. Taylor, J. Curtis, and P. P. Pasteris, 2008: Physiographically sensitive mapping of climatological temperature and precipitation across the conterminous United States. Int J. Climatol., 28, 2031-2064, https://doi.org/10.1002/joc.1688.

Deblauwe, V., and Coauthors, 2016: Remotely sensed temperature and precipitation data improve species distribution modelling in the tropics. Global Ecol. Biogeogr., 25, 443-454, https://doi.org/ 10.1111/geb.12426.

Duan, Y., A. M. Wilson, and A. P. Barros, 2015: Scoping a field experiment: Error diagnostics of TRMM precipitation radar estimates in complex terrain as a basis for IPHEx2014. Hydrol. Earth Syst. Sci., 19, 1501-1520, https://doi.org/10.5194/hess-19-1501-2015.

Durden, S. L., Z. S. Haddad, A. Kitiyakara, and F. K. Li, 1998: Effects of nonuniform beam filling on rainfall retrieval for the TRMM Precipitation Radar. J. Atmos. Oceanic Technol., 15, 635-646, https://doi.org/10.1175/1520-0426(1998)015<0635: $\mathrm{EONBFO}>2.0 . \mathrm{CO} ; 2$.

Farr, T. G., and Coauthors, 2007: The Shuttle Radar Topography Mission. Rev. Geophys., 45, RG2004, https://doi.org/10.1029/ 2005RG000183.

Fick, S. E., and R. J. Hijmans, 2017: WorldClim 2: New 1-km spatial resolution climate surfaces for global land areas. Int J. Climatol., 37, 4302-4315, https://doi.org/10.1002/joc.5086.

Fujinami, H., T. Sato, H. Kanamori, and F. Murata, 2017: Contrasting features of monsoon precipitation around the Meghalaya Plateau under westerly and easterly regimes. J. Geophys. Res. Atmos., 122, 9591-9610, https://doi.org/ 10.1002/2016JD026116.

Funk, C., and Coauthors, 2015a: The climate hazards infrared precipitation with stations-A new environmental record for monitoring extremes. Sci. Data, 2, 150066, https://doi.org/ 10.1038/sdata.2015.66.

- , A. Verdin, J. Michaelsen, P. Peterson, D. Pedreros, and G. Husak, 2015b: A global satellite-assisted precipitation climatology. Earth Syst. Sci. Data, 7, 275-287, https://doi.org/ 10.5194/essd-7-275-2015.

GEO, 2005: Global Earth Observation System of Systems (GEOSS) 10-year implementation plan. Group on Earth Observations, Geneva, Switzerland, 11 pp., https://www.earthobservations. org/documents/10-Year\%20Implementation\%20Plan.pdf.

Guilloteau, C., E. Foufoula-Georgiou, and C. D. Kummerow, 2017: Global multiscale evaluation of satellite passive microwave retrieval of precipitation during the TRMM and GPM eras: Effective resolution and regional diagnostics for future algo- rithm development. J. Hydrometeor., 18, 3051-3070, https:// doi.org/10.1175/JHM-D-17-0087.1.

Hamada, A., and Y. N. Takayabu, 2014: A removal filter for suspicious extreme rainfall profiles in TRMM PR 2A25 version 7 data. J. Appl. Meteor. Climatol., 53, 1252-1271, https://doi.org/ 10.1175/JAMC-D-13-099.1.

— and - 2016: Improvements in detection of light precipitation with the Global Precipitation Measurement Dual-Frequency Precipitation Radar (GPM DPR). J. Atmos. Oceanic Technol., 33, 653-666, https://doi.org/10.1175/JTECH-D-15-0097.1.

, C. Liu, and E. J. Zipser, 2015: Weak linkage between the heaviest rainfall and tallest storms. Nat. Commun., 6, 6213, https://doi.org/10.1038/ncomms7213.

Harris, D., E. Foufoula-Georgiou, and C. Kummerow, 2003: Effects of underrepresented hydrometeor variability and partial beam filling on microwave brightness temperatures for rainfall retrieval. J. Geophys. Res., 108, 8380, https://doi.org/10.1029/ 2001JD001144.

Heymsfield, G. M., B. Geerts, and L. Tian, 2000: TRMM Precipitation Radar reflectivity profiles as compared with high-resolution airborne and ground-based radar measurements. J. Appl. Meteor., 39, 2080-2102, https://doi.org/10.1175/1520-0450(2001)040<2080: TPRRPA $>2.0 . \mathrm{CO} ; 2$.

Hijmans, R. J., S. E. Cameron, J. L. Parra, P. G. Jones, and A. Jarvis, 2005: Very high resolution interpolated climate surfaces for global land areas. Int. J. Climatol., 25, 1965-1978, https://doi.org/10.1002/joc.1276.

Hirose, M., 2018: Ultra-high-resolution TRMM PR precipitation database, version 1. Meijo University, accessed 20 April 2018, https://www.rain-clim.com.

, R. Oki, D. A. Short, and K. Nakamura, 2009: Regional characteristics of scale-based precipitation systems from ten years of TRMM PR data. J. Meteor. Soc. Japan, 87A, 353-368, https://doi.org/10.2151/jmsj.87A.353.

, Y. N. Takayabu, A. Hamada, S. Shige, and M. K. Yamamoto, 2017a: Impact of long-term observation on the sampling characteristics of TRMM PR precipitation. J. Appl. Meteor. Climatol., 56, 713-723, https://doi.org/10.1175/JAMC-D-16-0115.1.

,,,---- , and,$- 2017 \mathrm{~b}$ : Spatial contrast of geographically induced rainfall observed by TRMM PR. J. Climate, 30, 4165-4184, https://doi.org/10.1175/JCLI-D16-0442.1.

Iguchi, T., K. Kozu, J. Kwiatkowski, J. Awaka, and K. Okamoto, 2009: Uncertainties in the rain profiling algorithm for the TRMM Precipitation Radar. J. Meteor. Soc. Japan, 87A, 1-30, https://doi.org/10.2151/jmsj.87A.1.

- S. Seto, R. Meneghini, N. Yoshida, J. Awaka, and T. Kubota, 2010: GPM/DPR level-2 algorithm theoretical basis document. NASA Rep., 72 pp., https://pmm.nasa.gov/sites/default/ files/document_files/ATBD_GPM_DPR_n3_dec15.pdf.

Isotta, F. A., and Coauthors, 2014: The climate of daily precipitation in the Alps: Development and analysis of a highresolution grid dataset from pan-Alpine rain-gauge data. Int. J. Climatol., 34, 1657-1675, https://doi.org/10.1002/ joc.3794.

Kamiguchi, K., O. Arakawa, A. Kioh, A. Yatagai, A. Hamada, and N. Yasutomi, 2010: Development of APHRO_JP, the first Japanese high-resolution daily precipitation product for more than 100 years. Hydrol. Res. Lett., 4, 60-64, https://doi.org/ 10.3178/hrl.4.60.

Karger, D. N., and Coauthors, 2017: Climatologies at high resolution for the earth's land surface areas. Sci. Data, 4, 170122, https://doi.org/10.1038/sdata.2017.122. 
Kirschbaum, D. B., and Coauthors, 2017: NASA's remotely sensed precipitation. Bull. Amer. Meteor. Soc., 98, 1169-1184, https:// doi.org/10.1175/BAMS-D-15-00296.1.

Kirstetter, P.-E., Y. Hong, J. J. Gourley, M. Schwaller, W. Petersen, and J. Zhang, 2013: Comparison of TRMM 2A25 products, version 6 and version 7, with NOAA/NSSL ground radar-based National Mosaic QPE. J. Hydrometeor., 14, 661669, https://doi.org/10.1175/JHM-D-12-030.1.

,,,,,----- and Q. Cao, 2015: Impact of sub-pixel rainfall variability on spaceborne precipitation estimation: Evaluating the TRMM 2A25 product. Quart. J. Roy. Meteor. Soc., 141, 953-966, https://doi.org/10.1002/qj.2416.

Maidment, R. I., and Coauthors, 2017: Data descriptor: A new, long-term daily satellite-based rainfall dataset for operational monitoring in Africa. Sci. Data, 4, 170063, https://doi.org/ 10.1038/sdata.2017.63.

Mega, T., and S. Shige, 2016: Improvements of rain/no-rain classification methods for microwave radiometer over coasts by dynamic surface-type classification. J. Atmos. Oceanic Technol., 33, 1257-1270, https://doi.org/10.1175/JTECH-D-15-0127.1.

Mei, Y., E. I. Nikolopoulos, E. N. Anagnostou, D. Zoccatelli, and M. Borga, 2016: Error analysis of satellite precipitation-driven modeling of flood events in complex Alpine terrain. Remote Sens., 8, 293, https://doi.org/10.3390/rs8040293.

Minder, J. M., D. R. Durran, G. H. Roe, and A. M. Anders, 2008: The climatology of small-scale orographic precipitation over the Olympic Mountains: Patterns and processes. Quart. J. Roy. Meteor. Soc., 134, 817-839, https://doi.org/10.1002/qj.258.

Mott, R., and M. Lehning, 2010: Meteorological modeling of very high-resolution wind fields and snow deposition for mountains. J. Hydrometeor., 11, 934-949, https://doi.org/10.1175/ 2010JHM1216.1.

Murata, F., T. Terao, T. Hayashi, H. Asada, and J. Matsumoto, 2008: Relationship between atmospheric conditions at Dhaka, Bangladesh, and rainfall at Cherrapunjee, India. Nat. Hazards, 44, 399-410, https://doi.org/10.1007/s11069-007-9125-2.

Mutke, J., R. Jacobs, K. Meyers, T. Henning, and M. Weigend, 2014: Diversity patterns of selected Andean plant groups correspond to topography and habitat dynamics, not orogeny. Front. Genet., 5, https://doi.org/10.3389/fgene.2014.00351.

NASA, 2007: Tropical Rainfall Measuring Mission (TRMM) senior review proposal. NASA Rep., 47 pp., https://pmm.nasa.gov/ sites/default/files/document_files/TRMMSenRev2007_pub.pdf.

- 2008: TRMM TMI level 1B algorithm version 1. NASA Algorithm Theoretical Basis Document (ATBD), 40 pp., https:// docserver.gesdisc.eosdis.nasa.gov/repository/Mission/TRMM/ 3.3_Product_Documentation/3.3.4_Product_Gen_Algorithms/ L1B11ATBD_V1.pdf.

Nesbitt, S. W., and A. M. Anders, 2009: Very high resolution precipitation climatologies from the Tropical Rainfall Measuring Mission Precipitation Radar. Geophys. Res. Lett., 36, L15815, https://doi.org/10.1029/2009GL038026.

Prat, O. P., and A. P. Barros, 2010: Assessing satellite-based precipitation estimates in the southern Appalachian Mountains using rain gauges and TRMM PR. Adv. Geosci., 25, 143-153, https://doi.org/10.5194/adgeo-25-143-2010.

Prokop, P., and A. Walanus, 2015: Variation in the orographic extreme rain events over the Meghalaya hills in northeast India in the two halves of the twentieth century. Theor. Appl. Climatol., 121, 389-399, https://doi.org/10.1007/ s00704-014-1224-x.

Schauwecker, S., M. Rohrer, M. Schwarb, C. Huggel, A. P. Dimri, and N. Salzmann, 2016: Estimation of snowfall limit for the
Kashmir valley, Indian Himalayas, with TRMM PR bright band information. Meteor. Z., 25, 501-509, https://doi.org/ 10.1127/metz/2016/0738.

Schneider, U., A. Becker, P. Finger, A. Meyer-Christoffer, M. Ziese, and B. Rudolf, 2014: GPCC's new land surface precipitation climatology based on quality-controlled in situ data and its role in quantifying the global water cycle. Theor. Appl. Climatol., 115, 15-40, https://doi.org/10.1007/s00704-013-0860-x.

,,,,---- B. Rudolf, and M. Ziese, 2015: GPCC full data reanalysis version 7.0 at $0.5^{\circ}$ : Monthly land-surface precipitation from rain gauges built on GTS based and historic data. NCAR Data Research Archive, Boulder, CO, accessed 20 August 2016, https://doi.org/10.5065/D6000072.

Seo, E.-K., S. Hristova-Veleva, G. Liu, M.-L. Ou, and G.-H. Ryu, 2015: Long-term comparison of collocated instantaneous rain retrievals from the TRMM Microwave Imager and Precipitation Radar over the ocean. J. Appl. Meteor. Climatol., 54, 867-879, https://doi.org/10.1175/JAMC-D-14-0235.1.

Shea, J. M., W. W. Immerzeel, P. Wagnon, C. Vincent, and S. Bajracharya, 2015: Modelling glacier change in the Everest region, Nepal Himalaya. Cryosphere, 9, 1105-1128, https:// doi.org/10.5194/tc-9-1105-2015.

Shige, S., and C. D. Kummerow, 2016: Precipitation-top heights of heavy orographic rainfall in the Asian monsoon region. J. Atmos. Sci., 73, 3009-3024, https://doi.org/10.1175/JAS-D-15-0271.1.

Short, D. A., M. Hirose, and K. Nakamura, 2009: An interpretation of TRMM radar observations of shallow convection with a rain cell model. J. Meteor. Soc. Japan, 87A, 67-81, https://doi.org/ 10.2151/jmsj.87A.67.

Sugimoto, S., and H. G. Takahashi, 2016: Effect of spatial resolution and cumulus parameterization on simulated precipitation over South Asia. SOLA, 12A, 7-12, https://doi.org/10.2151/ sola.12A-002.

Takahara, H., and J. Matsumoto, 2002: Climatological study of precipitation distribution in Yaku-shima Island, southern Japan (in Japanese). J. Geogr., 111, 726-746, https://doi.org/ 10.5026/jgeography.111.5_726.

Takahashi, N., and R. Oki, 2010: Development of a digital elevation map using TRMM/PR data. Int. Arch. Photogramm. Remote Sens. Spat. Inf. Sci., XXXVIII (Part 8), 150-153, http://www.isprs. org/proceedings/XXXVIII/part8/pdf/NTS21_20100607115800.pdf.

Terao, T., M. N. Islam, T. Hayashi, and T. Oka, 2006: Nocturnal jet and its effects on early morning rainfall peak over northeastern Bangladesh during the summer monsoon season. Geophys. Res. Lett., 33, L18806, https://doi.org/10.1029/ 2006GL026156.

— , and Coauthors, 2017: Direct validation of TRMM/PR near surface rain over the northeastern Indian subcontinent using a tipping bucket raingauge network. SOLA, 13, 157-162.

TRMM Precipitation Radar Team, 2011: Tropical Rainfall Measuring Mission (TRMM) Precipitation Radar algorithm: Instruction manual for version 7. JAXA-NASA Rep., 170 pp., http://www. eorc.jaxa.jp/TRMM/documents/PR_algorithm_product_information/ pr_manual/PR_Instruction_Manual_V7_L1.pdf.

Tustison, B., E. Foufoula-Georgiou, and D. Harris, 2003: Scale-recursive estimation for multisensory quantitative precipitation forecast verification: A preliminary assessment. J. Geophys. Res., 108, 8377, https://doi.org/10.1029/2001JD001073.

Vernimmen, R. R. E., A. Hooijer, M. Mamenun, E. Aldrian, and A. I. J. M. Van Dijk, 2012: Evaluation and bias correction of satellite rainfall data for drought monitoring in Indonesia. Hydrol. Earth Syst. Sci., 16, 133-146, https://doi.org/10.5194/ hess-16-133-2012. 
Wang, T., A. Hamann, D. Spittlehouse, and C. Carroll, 2016: Locally downscaled and spatially customizable climate data for historical and future periods for North America. PLOS ONE, 11, e0156720, https://doi.org/10.1371/journal.pone.0156720.

WMO, 2009: Management of Water Resources and Application of Hydrological Practices. Vol. II. Guide to Hydrological Practices, 6th ed., WMO-No. 168, 300 pp.

Yamamoto, M. K., F. A. Furuzawa, A. Higuchi, and K. Nakamura, 2008: Comparison of diurnal variations in precipitation systems observed by TRMM PR, TMI, and VIRS. J. Climate, $\mathbf{2 1}$, 4011-4028, https://doi.org/10.1175/2007JCLI2079.1.
Yatagai, A., K. Kamiguchi, O. Arakawa, A. Hamada, N. Yasutomi, and A. Kitoh, 2012: APHRODITE: Constructing a long-term daily gridded precipitation dataset for Asia based on a dense network of rain gauges. Bull. Amer. Meteor. Soc., 93, 1401-1415, https://doi.org/10.1175/BAMS-D-11-00122.1.

Zhang, L., D. Lu, S. Duan, and J. Liu, 2004: Small-scale rain nonuniformity and its effect on evaluation of nonuniform beam-filling error for spaceborne radar rain measurement. J. Atmos. Oceanic Technol., 21, 11901197, https://doi.org/10.1175/1520-0426(2004)021<1190: SRNAIE $>2.0 . \mathrm{CO} ; 2$. 